\title{
Spatio-temporal assessment and economic analysis of a grid-connected island province toward a $35 \%$ or greater domestic renewable energy portfolio: a case in Bohol, Philippines
}

\author{
Dave J. Pojadas ${ }^{1,2}$ (D) Michael Lochinvar Sim Abundo ${ }^{3,4}$
}

Received: 5 August 2020 / Accepted: 18 November 2020 / Published online: 1 January 2021

(c) Islamic Azad University 2021

\begin{abstract}
The year 2020 marks the start of the implementation of the Renewable Portfolio Standards in the Philippines. To raise the country's renewable energy (RE) share to $35 \%$ by 2030 (aspirational target), an annual minimum incremental RE of $1 \%$ has been imposed to all mandated participants. This local-level policy implementation has allowed the assessment of RE resource adequacy to be carried out on a smaller geographical scale (i.e., province level). The case for grid-connected island provinces, such as our study area, can be more interesting because of the opportunity to self-sustainable energy production. In this paper, we assess the adequacy of domestic RE resources of Bohol province to reach this target by estimating the technical potential of solar, wind, biomass, and hydropower using spatio-temporal datasets. Then, for every identified potential RE project, we calculate the busbar levelized cost. We also evaluate the province's base RE share to assess the extent to which the technical potential can improve its RE penetration in four distinct domestic and imported energy generation scenarios. With 20 different scenarios of additional RE capacity, we generate RE portfolios for the minimum target RE share (35\%), as well as the 50\% and maximum. The results revealed that, when the country's RE penetration continues, Bohol's hydropower potential is not enough to meet the 35\% target. Seasonal renewables are also insufficient for a 50\% target. In several scenarios, the province's energy self-sustainability can be possible at reasonable costs when variable RE technologies are included in the portfolio.
\end{abstract}

Keywords Renewable energy $\cdot$ Philippines $\cdot$ Spatio-temporal assessment $\cdot$ Economic analysis $\cdot$ Renewable portfolio standards $\cdot$ LCOE

\section{List of symbols}

$E_{s, k}$

Annual energy generation of solar project $k$ (MWh)

$\mathrm{CF}_{s, k} \quad$ Capacity factor for solar project $k$

$\mathrm{PC}_{s, k}$

$T$

$f(u)$ $8760 \mathrm{H}$
Installed capacity of solar project $k(\mathrm{MW}) \quad \mathrm{PE}(u)$

Rayleigh probability distribution of a wind class at wind speed $u$

Dave J. Pojadas

dabio_pjds@yahoo.com

1 School of Engineering, University of San Carlos, Cebu City, Philippines

2 Electrical Engineering Department, Bohol Island State University, Tagbilaran City, Philippines

3 College of Engineering, Nanyang Technological University, 50 Nanyang Avenue, Singapore 639798, Singapore

4 OceanPixel Pte Ltd, The NEST, NTU Innovation Centre, 71 Nanyang Drive, Singapore 638075, Singapore

$U_{\mathrm{m}}$
$P(u)$
$\mathrm{PE}(u)$
$\mathrm{EE}(u)$
$P_{\text {rated }}$
$\mathrm{CF} w(u)$
$\mathrm{CF}_{w, k}$
$\mathrm{PC}_{w, k}$
$E_{w, k}$
$\mathrm{CF}_{b, k}$
$\mathrm{PC}_{b, k}$

Average wind speed $(\mathrm{m} / \mathrm{s})$

Power at wind speed $u$ derived from the power curve of the selected wind turbine $(\mathrm{kW})$

Power production of the selected wind turbine at a particular point on an annual basis $(\mathrm{kW})$

Annual expected wind energy generation of the turbine $(\mathrm{kWh})$

Rated power of the selected wind turbine $(\mathrm{kW})$

Capacity factor of the selected wind turbine at wind speed $u$

Capacity factor for wind project $k$ Installed capacity of wind project $k$ (MW) Annual energy generation of wind project $k$ (MWh)

Capacity factor for bioenergy project $k$ Installed capacity of bioenergy project $k$ (MW) 


\begin{tabular}{|c|c|}
\hline$E_{b, k}$ & $\begin{array}{l}\text { Annual energy generation of bioenergy } \\
\text { project } k(\mathrm{MWh})\end{array}$ \\
\hline $\mathrm{PC}_{h, k}$ & $\begin{array}{l}\text { Installed capacity of hydropower project } k \\
\text { (MW) }\end{array}$ \\
\hline$\rho$ & Density of water at $1000 \mathrm{~kg} / \mathrm{m}^{3}$ \\
\hline$g$ & Gravitational acceleration at $9.81 \mathrm{~m} / \mathrm{s}^{2}$ \\
\hline$\eta_{\mathrm{h}}$ & Overall efficiency of the hydropower plant \\
\hline$Q_{\text {eff }, k}$ & $\begin{array}{l}\text { Effective discharge flow rate of hydro } \\
\text { project } k \text { in } \mathrm{m}^{3} / \mathrm{s} \text { computed from FDC }\end{array}$ \\
\hline$h_{\text {net }, k}$ & Net head of hydro project $k(\mathrm{~m})$ \\
\hline$E_{h, k}$ & $\begin{array}{l}\text { Annual energy generation of hydropower } \\
\text { project } k(\mathrm{MWh})\end{array}$ \\
\hline $\mathrm{CF}_{h, k}$ & Capacity factor for hydropower project $k$ \\
\hline CRF & Capital recovery factor \\
\hline$I_{g e n, m}$ & $\begin{array}{l}\text { Unit capital expenditure of particular } \\
\text { generation technology } m(\mathrm{Php} / \mathrm{MW})\end{array}$ \\
\hline$O_{g e n . f x x, m}$ & $\begin{array}{l}\text { Fixed cost to operate and maintain a } \\
\text { project } k \text { of particular technology type } m \\
\text { (Php/MWh-year) }\end{array}$ \\
\hline$O_{g e n, \mathrm{var}, m}$ & $\begin{array}{l}\text { Variable cost to operate and maintain a } \\
\text { project k of particular technology type } m \\
\text { (Php/MWh) }\end{array}$ \\
\hline$C F_{m, k}$ & $\begin{array}{l}\text { Capacity factor of a particular project } k \text { of } \\
\text { particular technology } m\end{array}$ \\
\hline$I_{\text {spur }, m}$ & $\begin{array}{l}\text { Unit capital cost of spur line construc- } \\
\text { tion for a particular technology } m(\mathrm{Php} / \\
\text { MW-km) }\end{array}$ \\
\hline$I_{r d, m}$ & $\begin{array}{l}\text { Unit capital cost to construct access road } \\
(\mathrm{Php} / \mathrm{km})\end{array}$ \\
\hline$I_{s}$ & $\begin{array}{l}\text { Unit capital cost for two substations (Php/ } \\
\text { MW) }\end{array}$ \\
\hline$L_{\text {spur }, m, k}$ & $\begin{array}{l}\text { Estimated length of spur line of project } k \\
\text { of particular technology type } m(\mathrm{~km})\end{array}$ \\
\hline$L_{r d, m, k}$ & $\begin{array}{l}\text { Estimated length of access road for project } \\
k \text { of particular technology type } m(\mathrm{~km})\end{array}$ \\
\hline$N$ & Project lifespan (years) \\
\hline$i$ & $\begin{array}{l}\text { Weighted average of the cost of capital } \\
\text { (WACC) }\end{array}$ \\
\hline $\mathrm{RE}_{\text {import }}$ & Annual RE import of the study area \\
\hline NONRE $_{\text {import }}$ & Annual non-RE import of the study area \\
\hline$\% \mathrm{RE}_{\text {Phils }}$ & $\begin{array}{l}\text { Percent renewable energy in the } \\
\text { Philippines }\end{array}$ \\
\hline$\%$ NONRE $_{\text {Phils }}$ & $\begin{array}{l}\text { Percent non-renewable energy in the } \\
\text { Philippines }\end{array}$ \\
\hline EP & $\begin{array}{l}\text { Annual energy purchase of the study area } \\
(\mathrm{MWh})\end{array}$ \\
\hline DEC & $\begin{array}{l}\text { Contribution of domestic energy genera- } \\
\text { tion to the total energy purchase (MWh) }\end{array}$ \\
\hline $\mathrm{RE}_{\mathrm{in}, \mathrm{ex}}$ & $\begin{array}{l}\text { Energy generation of existing domestic } \\
\text { renewable power plant (MWh) }\end{array}$ \\
\hline $\mathrm{NRE}_{\text {in,ex }}$ & $\begin{array}{l}\text { Energy generation of existing domestic } \\
\text { non-renewable power plant (MWh) }\end{array}$ \\
\hline
\end{tabular}
$\mathrm{RE}_{\text {in,new }}$
Energy generation of new domestic renew- able power plant (MWh)
$\mathrm{GHG}_{\text {coal }} \quad$ Unit lifecycle tons of equivalent carbon emissions for coal-based generation (tCO2e/MWh)
$\mathrm{GHG}_{m} \quad$ Unit lifecycle tons of equivalent car- bon emissions for RE-based generation (tCO2e/MWh)
$E_{m} \quad$ Total energy generation of a particular RE technology $m$ in a particular portfolio (MWh)

$\begin{array}{ll}\text { Bohol\%RE } & \text { RE penetration of the study area } \\ \mathrm{RE}_{\text {domestic }} & \begin{array}{l}\text { Domestic annual RE generation of the } \\ \text { study area }(\mathrm{MWh})\end{array} \\ \mathrm{E}_{\text {total }} & \begin{array}{l}\text { Total domestic energy generation of the } \\ \text { study area (MWh) }\end{array}\end{array}$

\section{Introduction}

With abundant natural resources, the Philippines can sustain a substantial fraction of its electricity needs, utilizing solar, wind, biomass, hydro, marine, and geothermal power. The enactment of the Electric Power Industry Reform Act of 2001 (EPIRA Law) not only restructured the country's power industry from the vertically integrated state-owned generation-transmission system into a neo-liberal deregulated overall sector, but also sketched an avenue for the renewable energy utilization. In EPIRA Law, policy of the state has been declared to guarantee socially and environmentally compatible energy sources and infrastructure. The utilization of indigenous and new and renewable energy resources in power generation is primarily promoted to reduce dependence on imported energy. Upon the subsequent enactment of the Renewable Energy Act of 2008 (RE Law), a more detailed road has been drawn-opening pathways for development and innovation, utilization, and commercialization in this arena. RE Law has provided a more pleasant business environment for renewable energy-offering fiscal and non-fiscal incentives to merchants and developers. It had also outlined policies and programs such as Renewable Portfolio Standards (RPS), Feed-In Tariff, and National Renewable Energy Program not only to attract investment and promote more competition in the industry, but also to weave a holistic conversion of the industry in the hope of freeing the country from dependence on imported energy.

The year 2020 marks the starting period (year zero) of the implementation of the RPS in the country. RPS is a marketbased policy that requires all mandated participants (e.g., distribution utilities, suppliers of electricity for the contestable market, and generating companies) to source a portion of their energy supply from eligible RE resources [1]. The 
rationale behind RPS implementation is the aspiration of the country to raise RE share in its energy mix to $35 \%$ by 2030 by imposing a minimum annual incremental RE (AMI) percentage of $1 \%$ on all mandated participants. The share of RE in 2008, when the RE Law was enacted, is approximately $34 \%$, and since then there has been a dramatic decline of RE shares each year (see Fig. 1, source: [2]). The increase in demand brought by technological advancement, economic activities, and population growth appeared to outpace the RE capacity increase. As a result, the share of coal-based energy generation doubled in 10 years, despite the Department of Energy's (DOE) unprecedented efforts to promote RE.

Though RPS is implemented nationwide, policy compliance is evaluated at the local level. Imposing an AMI of $1 \%$ to all mandated participants means every distribution utility (DU), including retail electricity suppliers, etc., has to supply their respective customers with more renewable-based generation each year by either making bilateral contracts with any eligible RE facilities or investing in their indigenous RE resources. Since previous RE contracts beginning in the transition year (2019) can be converted into RE certificates and can be retired for this purpose, DUs and other participants are not concerned about the near-term compliance (up to 2022). However, in the medium and long term, these power industry players must enter into contracts with qualifying RE facilities or retire RE certificates from their own RE generation facilities. In either case, there is high certainty on demand for RE in the country over the next 10 years, so a faster roll-out of $\mathrm{RE}$ generation projects is also expected to take place.
To some degree, enforcing a 1\% AMI across all mandated participants means that the RE resource adequacy assessment can be best carried out on a smaller geographical scale (i.e., province level, regional). In this paper, we evaluate the feasibility of three DUs in a grid-connected island province to reach not the AMI but the $35 \%$ goal as a unit. We investigate this compliance as well as the possibility of self-sustaining energy production when new RE generation facilities are being installed within or outside the province. In any case, the main objective of this study is to find the extent to which the technical potential of solar, wind, biomass, and hydropower can improve the RE penetration of the study area. The methodology we presented can be used by other grid-connected island provinces in obtaining a similar objective.

\section{The study area}

Bohol is an island province in the Visayas group of islands, whose total area is approximately $4000 \mathrm{~km}^{2}$. It is one of the 81 provinces in the Philippines composed of 1109 barangays, 47 component municipalities, and a lone city, Tagbilaran (in three legislative districts). As a tropical province, Bohol has abundant solar energy resources with annual global horizontal irradiance ranging from 1500 to 1900 kilowatt-hours per square meter. Bohol's wind resource is also plentiful; some areas have wind classes above $7 \mathrm{mls}$. As an agro-industrial province, Bohol's primary agricultural products include rice, corn, coconut, cassava, and oil palma potential for biopower energy production. It also has 11

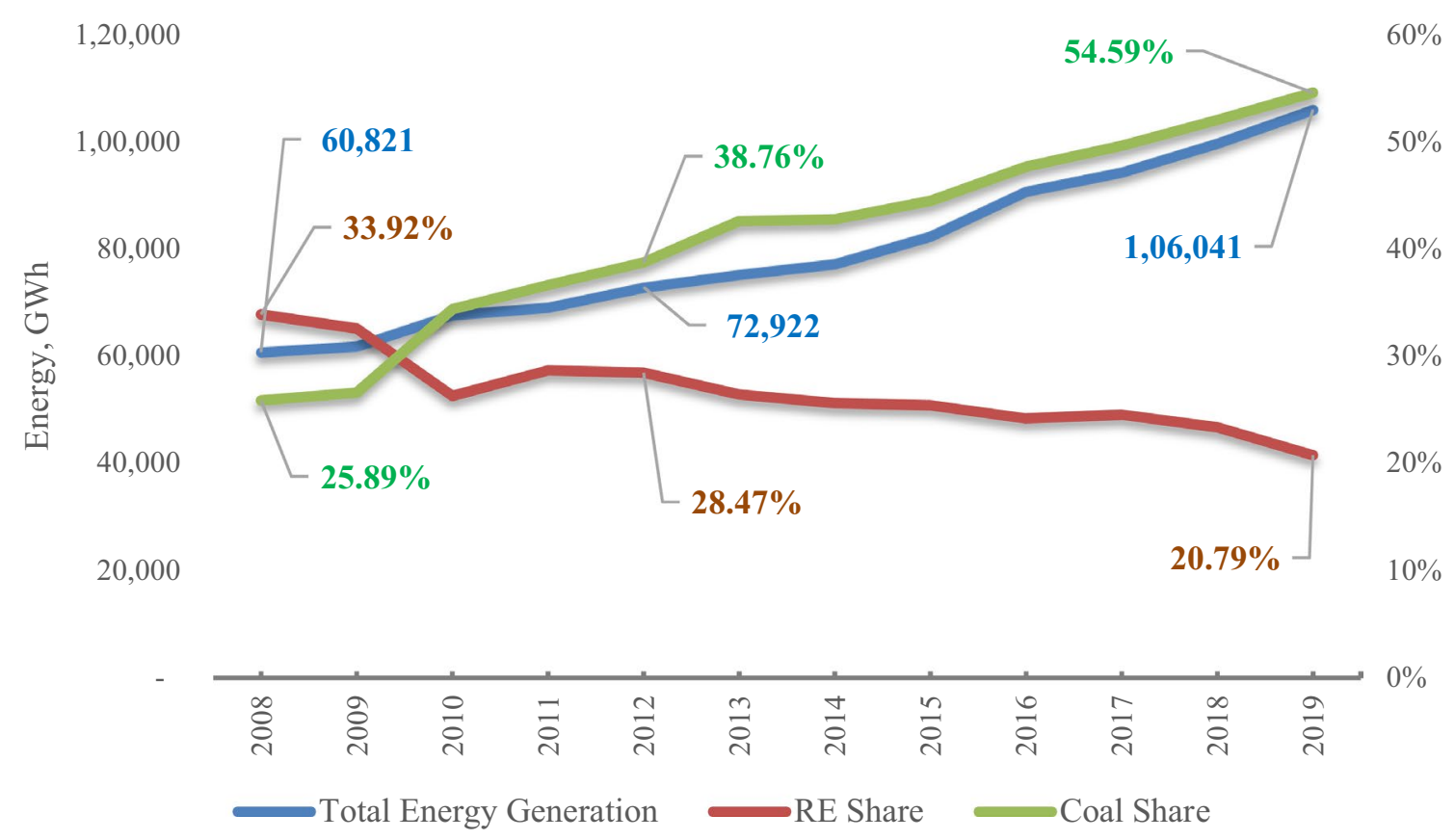

Fig. 1 2008-2019 Philippine energy generation share: RE based versus coal based ( Source: Department of Energy [2]) 
watersheds: Abatan, Alijawan, Caroud, Wahig-Inabanga, Ipil, Loboc, Lumbay, Manaba, Mualong, Panampan, and Soom, from which hydropower projects can be developed.

Bohol has a $16 \mathrm{MW}$ grid-connected diesel-fueled power plant located in Dampas District, Tagbilaran City (operating under the country's spot market), and three embedded mini-hydro projects located in the Loboc watershed. The province has a single link to the country's grid through a 100 MVA, 138 kV Leyte-Bohol Interconnection from which more than two-thirds of the province's supply is sourced (see Fig. 2). In 2018, a $32 \mathrm{MW}$ diesel/bunker-fired power barge located in Tapal Wharf, Ubay, was contracted as a dispatchable reserve-supporting the nearly overloaded Leyte-Bohol Interconnection. The province's demand is divided into three franchise areas under three DUs: Bohol Light Company, Inc. (BLCI), Bohol Electric Cooperative 1 (BOHECO 1), and Bohol Electric Cooperative 2 (BOHECO 2) [3].

The opening of an international airport in the province's tourism capital, Panglao municipality, in 2018, has increased tourist arrivals and boosted local economic activity. As a result, the peak demand increased remarkably from $80 \mathrm{MW}$ in 2018 to $101 \mathrm{MW}$ in 2019 [4]. Yet, the province's four inland power generation facilities only have a total dependable capacity of $20.4 \mathrm{MW}$ [3]. The failure to meet the single-outage contingency criterion and the inadequacy of the domestic power supply have made Bohol's power system vulnerable to tropical calamities such as typhoons and earthquakes. In 2013, for instance, the residents of the province survived a month-long power outage when typhoon Haiyan hit the neighboring Leyte province-highlighting the need for additional grid connection and domestic generation. Bohol's local government responded, and a multi-sectoral committee, the Bohol Energy Development Advisory Group (BEDAG), was created [3].

To resolve the province's energy security issue while recognizing its vision to be an eco-cultural tourism destination, an energy policy prohibiting all types of fossil-based energy generation in Bohol's soil was legislated in 2018. In this case, the province's energy demand can only be addressed with renewable energy sources. In light of the country's RPS policy, we used Bohol's power supply dilemma to illustrate a province-wide spatial assessment and economic analysis of $\mathrm{RE}$ resources. Due to the pressing demand to de-carbonize the power sector, we have also examined the effects of retiring the only inland oil-based power plant to the RE penetration of the province.

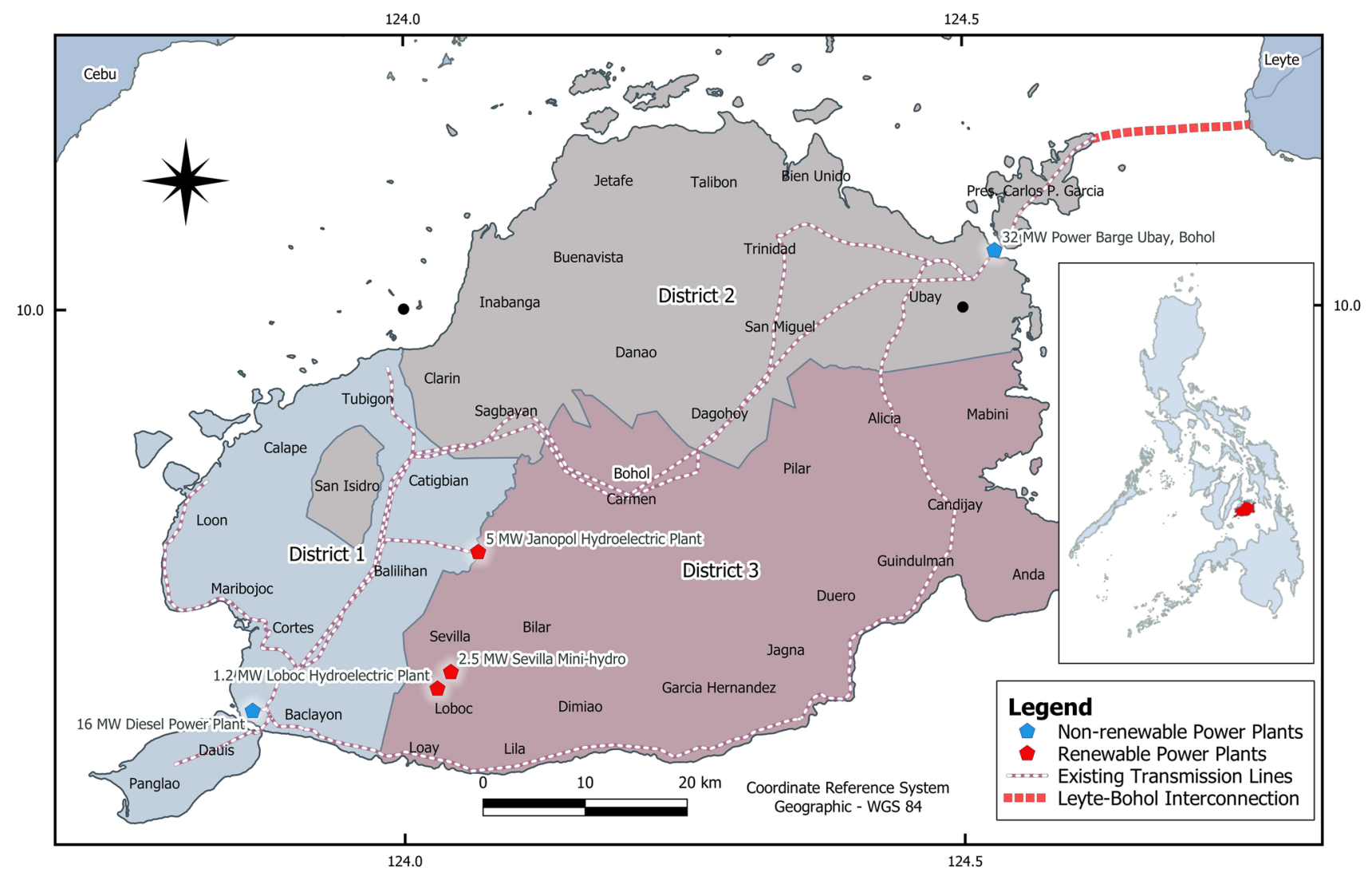

Fig. 2 Map of Bohol province with its existing power system (digitized in this study) 


\section{Related works}

\section{Spatial modeling of RE potential}

Spatial modeling of RE potential is generally intended to inform policymakers, energy researchers, or decision-makers about suitable energy projects' indicative locations. Estimation of the amount of energy, as well as all costs incurred in producing it, can be considered as additional information to support decision-making or policymaking. The macro-screening context discussed by Van Dael et al. [5] in their article is what we refer to here. The following subsections summarize the various studies related to spatial modeling of variable and seasonal RE.

\section{Variable renewable energy (VRE)}

Apart from generating energy that varies with the weather conditions, solar and wind technologies are considered variable because they produce energy that fluctuates in a relatively short period (i.e., minutes, seconds). In the literature, there is a prevalence of suitability studies or research that end up reporting the vast area where VREs can be deployed (where suitability map is the final output). The combination of the geographic information system and multi-criteria decision analysis (GIS-MCDA) appeared to be the most popular approach. For example, Refs. [6-9] used the analytical hierarchy process (AHP) and weighted overlay to identify areas suitable for wind farms in Saudi Arabia, India, Germany, and Greece. Reference [10] also used AHP and weighted overlay to find suitable solar installations in Karapinar, Turkey, while Refs. $[11,12]$ used a similar method to find sites ideal for solar and wind technologies in Songkhla, Thailand, and Southern England, respectively. Also, Ref. [13] utilized it for hybrid offshore wind and wave energy systems in Greece. Many research investigated the use of more sophisticated MCDA techniques to identify sites suitable for VRE projects in their respective study areas [14-23].

Aside from identifying the vast area of potential in the study area, some GIS-MCDA studies have also indicated a cost/financial analysis. For instance, Ref. [24] highlighted in their paper how they obtained the offshore wind suitability map for Egypt using AHP and weighted overlay. Still, they have estimated the capacity of three selected locations. Reference [25] used a similar method while also simulating a $10 \mathrm{MW}$ grid-connected solar PV in HOMER software. Reference [26] used the MCDA method to determine the most suitable area for offshore wind farm deployment in Hong Kong and calculated the installation cost of the three most suitable zones using three turbine models. Other GIS-MCDA studies have also estimated the technical potential using the technical parameters of technology considered [27-30]. Some studies were not using any known MCDA method but the spatial overlay of criteria. This can also be regarded as a spatial multicriteria approach, such as the case in Refs. [31-40]. While these studies used a combination of several criteria including technical, economic, social, environmental, and the likes, Ref. [38] used only atmospheric and meteorological inputs, while Ref. [41] estimated the solar irradiation using DEM and DSM considering cloud cover.

\section{Seasonal renewable energy (SRE)}

In addition to the variations in energy output due to weather conditions, hydropower's energy generation varies with a hydrological cycle that ranges over a larger period (i.e., year, month). That is why we regarded hydropower as "seasonal" in this study and for a similar reason, the bioenergy.

Hydropower is usually assessed in terms of head availability and effective discharge flow rate. Kusre et al. [42] estimated the flow rate using the SWAT2000 hydrological model and a bottom gradient of at least $2 \%$ to ensure sufficient potential head in their assessment of hydropower plants higher than $500 \mathrm{~kW}$ in Kopili river basin in Assam, India. Bódis et al. [43] assessed the technical potential of hydropower projects in Europe and identified the actual suitable sites of the proposed hydro stations using a novel GIS-based analysis of elevation and stream networks. Reference [44] utilized the SWAT model and spatial analysis to assess run-of-river hydropower potential in India's Mat River basin. Tarife et al. [45] estimated theoretical potential for the micro- and pico-hydropower in Misamis Occidental, Philippines using SWAT for discharge flow analysis and an enhanced algorithm for head availability determination. Garegnani et al. [46] also presented a tool that integrates all the legal, technical, and financial analysis in spatial analysis to find new small hydropower plants in Alpine Valleys. This tool can calculate the theoretical and planning potential, as well as the economic potential using NPV.

Meanwhile, the potential for energy production from biomass primarily depends on the availability of feedstock. Forest biomass, municipal solid wastes, agricultural residues, among others, can be transported, pre-processed, and used as fuel for bioenergy plants. Assessment of feedstock availability, as well as the collection and transportation of raw materials from the source to the energy production facility, are the common subjects of research in this field. For instance, Beccali et al. [47] developed a GIS-supported methodology to assess the technical and economic potential of residues coming from the pruning of olive groves, vineyards, and other crops for energy production in Sicily. Data on land use, digital terrain model, climatic types, geological substratum, 
etc. were used to assess biomass availability. Considering the cost of harvesting, collection, and transportation, they generated the supply curves of each biomass residue. Grilli et al. [48] developed a suite of add-ons in GRASS GIS capable of estimating the potential of forest biomass, hydro, and solar energy. Like the other modules, the module for biomass can find the power plant's location based on demand. They used NPV as a metric in the economic analysis.

In this research area, the GIS-MCDA approach has also been used. Van Dael et al. [5], for instance, used the AHP to identify suitable locations for the establishment of biomass projects in Limburg, Belgium. In Brazil, Teixeira et al. [49] used fuzzy logic to find appropriate zones of biomass activity. They developed a location-allocation model to minimize the cost associated with the transportation of raw materials.

\section{Estimation of energy generated from VREs}

On estimating the energy generated from VREs, the usual practice is the use of the product of capacity factor and installed capacity (and period), both of which are sensitive to the location and technology. Capacity factors can be obtained from the literature, simulated, or calculated from past energy generation records. Installed capacity, on the other hand, is usually estimated using power density (potential per area) in spatial modeling. However, unlike the capacity factor, the variation of power densities for VREs in the literature is broad, which may significantly affect any research or planning works. Deshmukh et al. [32] used power densities of 30 and $7.5 \mathrm{MW} / \mathrm{km}^{2}$ for solar PV, 9 and $2.25 \mathrm{MW} / \mathrm{km}^{2}$ for wind, and 17 and $4.25 \mathrm{MW} / \mathrm{km}^{2}$ with 6-h storage for CSP in their spatial estimation of wind and solar resources in India. Lopez et al. [50] used $48 \mathrm{MW} / \mathrm{km}^{2}$, $32.8 \mathrm{MW} / \mathrm{km}^{2}$, and $5 \mathrm{MW} / \mathrm{km}^{2}$ for their estimate of potential utility-scale solar PV, CSP, and wind projects in the USA, while Ref. [51] used empirical power density of $7 \mathrm{MW} / \mathrm{km}^{2}$ to calculate additional local wind potential. Also, Ref. [36] used $2 \mathrm{MW} / \mathrm{km}^{2}$ for wind, $48 \mathrm{MW} / \mathrm{km}^{2}$ for solar PV, and 22.38 to $49.26 \mathrm{MW} / \mathrm{km}^{2} \mathrm{CSP}$ technologies to estimate the total implementable potential of wind and solar energy in Afghanistan.

\section{Economic analysis}

Economic analysis of RE resources is conducted to aid and inform decision and policymaking. Using standard cost metrics, economic analysis can be done in a spatial and nonspatial environment. Spatial modeling studies, such as the case for Refs. [32, 34] used the levelized cost of electricity (LCOE), Ref. [37] the net present value (NPV), and Ref. [39] applied both the LCOE and NPV as their cost metric in their conduct of economic analysis. For offshore wind farms,
Refs. [52, 53] used the levelized production cost (LPC). Non-spatial studies also used similar cost metrics, such as the present value costs (PVC) [54] or both LCOE and PVC [55]. Our study used the LCOE, the estimated amount of money incurred for any particular energy-generating project to produce a standard amount of electricity over its expected lifetime [56], to generate the supply curves from which our RE portfolio analysis is based.

Here, our contribution to the literature of renewable energy research evolved. None of the current spatial modeling studies (with economic analysis) we reviewed had examined the extent to which RE potential could increase the RE penetration of the study area in detail similar to ours.

\section{Methods and data}

Using publicly known and digitized data, we built our methodology from the concept of the reV model [57] and the modification made by Deshmukh et al. [32] to the Multicriteria Analysis for Planning Renewable Energy (MAPRE) (see Fig. 3). The reV model is a modular platform for a detailed assessment of technical RE potential developed by the National Renewable Energy Laboratory (NREL). On the other end, MAPRE is a spatial energy system modeling framework developed by the Lawrence Berkeley National Laboratory [58]. The study objectives are: (1) to evaluate the upper-bound technical RE potential of the study area and (2) to find the extent to which the technical potential can improve its RE penetration in light of the country's RPS policy.

\section{Spatial assessment and estimation of technical potential}

This section outlines how we derive each RE technology's upper-bound technical potential from estimates of each developable project's energy generation. Using Boolean logic and simple mathematical operation, our method of combining geospatial data is similar to the procedure well documented in Ref. [36]. In our study, we used the opensource platform QGIS.

\section{Solar energy}

We assessed the potential for utility-scale solar PV projects in Bohol from the datasets of SOLARGIS [59]. Since Bohol has annual global horizontal irradiance ranging from 1500 to 1900 kilowatt-hour (kWh) per square meter, we did not apply any resource potential exclusions. We then merged all socioenvironmental restrictions with techno-economic exclusions (Table 1) to obtain all solar PV constraints. All potential solar 


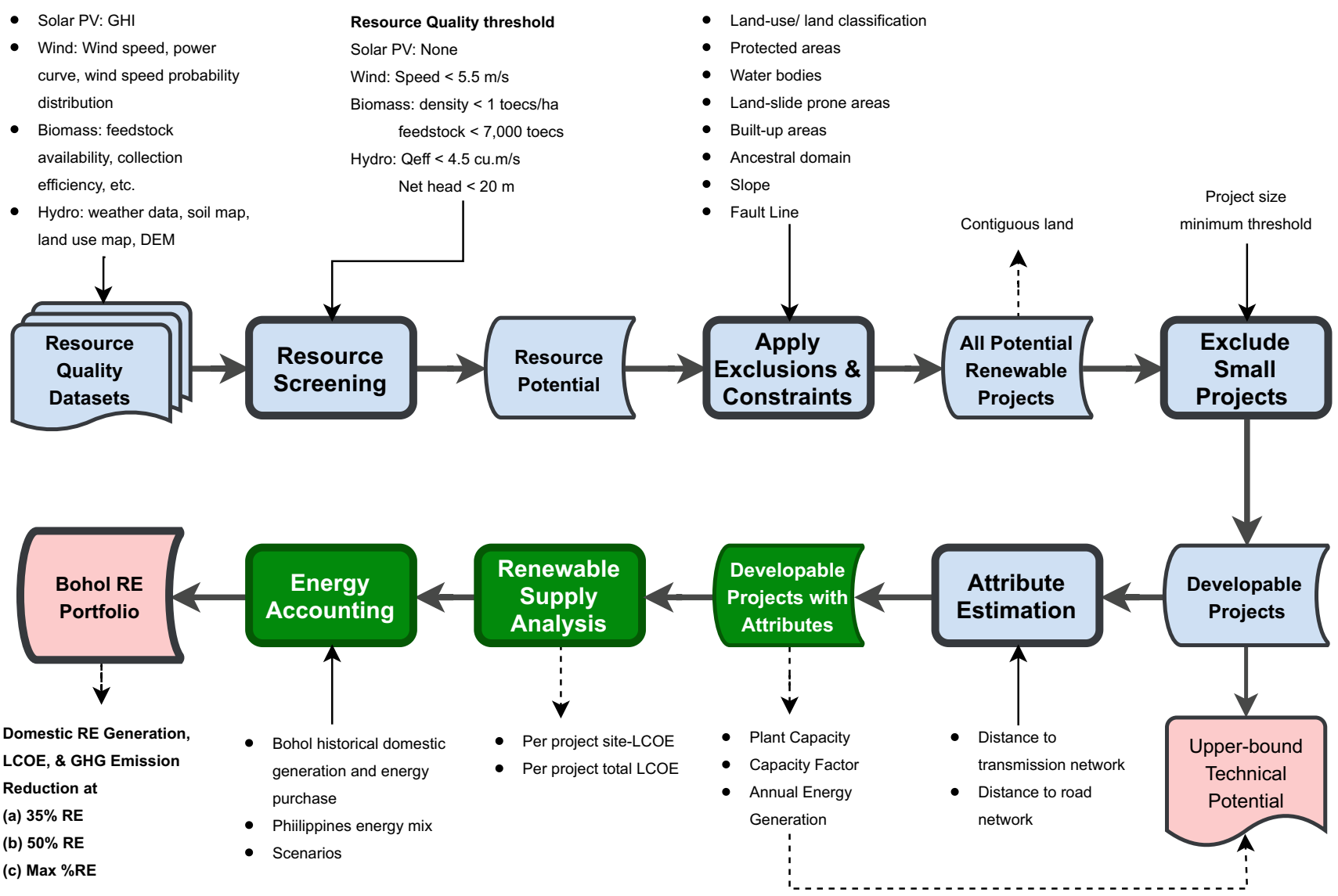

Fig. 3 The study methodology

PV projects were obtained from the remaining lands. Developable solar PV projects were obtained by excluding projects with a contiguous area smaller than 10 hectares $\left(0.1 \mathrm{~km}^{2}\right)$.

To estimate all developable solar PV projects' capacity, we used the empirical power density values of 7.5 and $30 \mathrm{MW} /$ $\mathrm{km}^{2}$ and applied a land-use discount factor of 0.80 [32]. We also digitized the area occupied by 30 existing utility-scale solar PV projects in the country (those visible in Google Earth Pro). We found their average power density to be about $1 \mathrm{MW} /$ hectare, so we also estimated the installed capacity of developable projects in Bohol using a power density of $100 \mathrm{MW} /$ $\mathrm{km}^{2}$. Then, we used the System Advisor Model (SAM) to estimate the capacity factor (CF). Since there is only one weather station available for the study area, we only got one capacity factor (14.6\%). We used it then to calculate the annual energy yield of all developable projects $k$ using Eq. 1.

$E_{s, k}=C F_{s, k} \times P C_{s, k} \times T$.

\section{Wind energy}

Wind energy's potential was assessed from data obtained in the Geospatial Toolkit of NREL (available at https://www. re-explorer.org/launch.html), adopting the process outlined by Mentis et al. [39]. Using the SIEMENS Gamesa 2 MW power curve and the Rayleigh probability distribution (Eq. 2) wind recurrence, the capacity factor of this turbine was calculated when installed in the Bohol wind regime (Eqs. 3-5) (at an availability factor $\mu$ of $97 \%$ ).

$$
\begin{aligned}
& f(u)=\left(\frac{\pi}{2}\right)\left(\frac{u}{U_{\mathrm{m}}^{2}}\right) \times \exp \left(-\left(\frac{\pi}{4}\right)\left(\frac{u}{U_{\mathrm{m}}}\right)^{2}\right) \\
& \operatorname{PE}(u)=\int_{U=0}^{U=\text { Cut out }} P(u) f(u)(\mathrm{d} u) \approx \sum_{\text {wind class }} P(u) f(u)
\end{aligned}
$$

$$
\mathrm{EE}(u)=\mu T \int_{U=0}^{U=\text { Cut out }} P(u) f(u)(\mathrm{d} u) \approx \mu T \sum_{\text {wind class }} P(u) f(u)
$$


Table 1 Constraints and restrictions used in this study to find suitable RE projects

\begin{tabular}{|c|c|c|c|c|}
\hline Criteria & Solar PV & Wind & Biopower & Hydropower \\
\hline Resource Potential & None & Wind speed $<5.5 \mathrm{~m} / \mathrm{s}$ & $\begin{array}{l}\text { Feedstock }<7000 \text { toecs, } \\
\text { biomass density }<0.8 \\
\text { toecs/ha }\end{array}$ & $\begin{array}{l}\text { Net head }<20 \mathrm{~m} \text {, } \\
\text { discharge } \\
\text { flow }<4.5 \mathrm{~m}^{3}\end{array}$ \\
\hline Land slope & $>10 \%$ & $>18 \%$ & $>10 \%$ & None \\
\hline Earthquake Fault Line & Within $1 \mathrm{~km}$ & Within $1 \mathrm{~km}$ & Within $1 \mathrm{~km}$ & None \\
\hline Land Slide Prone Areas & Avoid & Avoid & Avoid & None \\
\hline Protected Areas & Avoid & Avoid & Avoid & None \\
\hline Built-up Areas & Within $250 \mathrm{~m}$ & Avoid & Within $500 \mathrm{~m}$ & Not Applicable \\
\hline Waterbodies & Within $100 \mathrm{~m}$ & Within $100 \mathrm{~m}$ & Within $100 \mathrm{~m}$ & Not Applicable \\
\hline Ancestral Domain & Avoid & Avoid & Avoid & Avoid \\
\hline \multicolumn{5}{|l|}{ Land-use/land classification: } \\
\hline A-All irrigated areas & Avoid & None & Avoid & None \\
\hline $\begin{array}{l}\mathrm{B} \text {-All irrigable lands already covered by irrigation } \\
\text { projects with firm funding commitments }\end{array}$ & Avoid & None & Avoid & None \\
\hline $\begin{array}{l}\text { C-All alluvial plains highly suitable for agriculture, } \\
\text { mainly non-irrigated areas }\end{array}$ & None & None & None & None \\
\hline $\begin{array}{l}\text { D-Agro-industrial croplands or lands presently } \\
\text { planted for industrial crops that support the viability } \\
\text { of existing agricultural infrastructure and agro-based } \\
\text { enterprises }\end{array}$ & Avoid & None & None & None \\
\hline $\begin{array}{l}\text { E-High lands or areas located at the elevation of } \\
500 \mathrm{~m} \text { or above and have the potential of growing } \\
\text { semi-temperate and high-value crops }\end{array}$ & None & None & Avoid & None \\
\hline $\begin{array}{l}\text { F-All agricultural lands that are ecologically fragile, } \\
\text { the conversion of which to non-agricultural uses } \\
\text { will result in serious environmental degradation, and } \\
\text { mangrove and fish sanctuaries }\end{array}$ & Avoid & None & Avoid & None \\
\hline $\begin{array}{l}\text { G-All fishing areas as defined in the Fisheries Code } \\
\text { of } 1998\end{array}$ & None & None & None & None \\
\hline $\mathrm{H}$-Forest/Watershed Areas & Avoid & None & Avoid & None \\
\hline
\end{tabular}

$\mathrm{CF} w(u)=\mathrm{EE}(u) / P_{\text {rated }} T$.

At a threshold capacity factor of $32 \%$, the SIEMENS Gamesa $2 \mathrm{MW}$ turbine requires a wind speed of at least $5.5 \mathrm{~m} / \mathrm{s}$, so we excluded all land with wind speeds below this value. We then combined all socio-environmental restrictions and techno-economic exclusions for wind projects (Table 1) and identified all constrained areas. Combining resource potential and unconstrained regions, we obtained all potential wind projects from all remaining contiguous lands. Developable wind projects were obtained by excluding potential projects with a land area of less than $0.4 \mathrm{~km}^{2}$.

We used an empirical power density of 2.25 and $9 \mathrm{MW} /$ $\mathrm{km}^{2}$ and applied a land-use discount factor of 0.80 to estimate the capacity of all developable wind projects [32]. Each developable wind project's capacity factor was then calculated using the process outlined above-associating each project $k$ with the wind speed at its centroid (Eq. 6). We also estimated the annual energy yield using Eq. 7.
$\mathrm{CF}_{w, k}=\mathrm{EE}_{k} /\left(P_{\text {rated }} \times T\right)$

$E_{w, k}=\mathrm{CF}_{w, k} \times \mathrm{PC}_{w, k} \times T$.

\section{Bioenergy}

The potential for bioenergy production was assessed using the conventional approximation procedure (normalization of all biomass data into one equivalent feedstock). We used biomass density, which is the fraction of the normalized tons of available feedstock and the total land area, as a basis for creating areas of viable biomass activities (ABA).

We have adopted a screening procedure based on the clustering of potential municipal biomass activities. We estimated agro-crop residues for rice, corn, oil palm, and coconut using local data such as major crops growing, annual grain productivity, the pertinent ratios of usable and disposable components of the crop, and collection efficiency. 
Ramachandra et al. [60] had calculated the total bioenergy potential in Kolar, India, in terms of energy equivalent. However, in this paper, the biomass potential is calculated by converting all biomass feedstocks into tons of equivalent coconut shells (toecs) using their corresponding highheating values.

To obtain a list of eligible municipalities, we excluded all municipalities with biomass densities less than 0.8 toecs/ hectare. Manual grouping of adjacent municipalities into ABA follows zoning where the collection, pre-treatment, and feedstock delivery can be minimized. Each ABA should have at least 7000 toecs per year. We then calculated the average biomass density for each ABA and excluded zones with densities less than one toecs/hectare. We then identified the location of biomass production facilities (at least 4 hectares) for each ABA applying the socio-environmental restrictions and techno-economic constraints (Table 1). Biopower production facilities should be located near ABA's centroid and close to the road network and transmission infrastructure.

We used SAM to estimate each developable biomass project's installed capacity and capacity factor and calculated the annual energy yield using Eq. 8.

$E_{b, k}=\mathrm{CF}_{b, k} \times \mathrm{PC}_{b, k} \times T$.

\section{Hydropower}

The potential for mini run-of-the-river hydro projects of Bohol was assessed in terms of hydraulic head and discharge flow rate. The QSWAT hydrological model was used to obtain a discharge flow rate for all streams of the two largest watersheds (Wahig-Inabanga and Abatan) using the 30 m ASTER DEM, weather data, land-use map, and soil map. We excluded the Loboc watershed because all three existing hydropower projects in the province are located there. The flow duration curve (FDC) of each stream was then generated, and the effective discharge was calculated on the assumption of 50\% flow exceedance. Eligible streams were then obtained by excluding stream networks with an effective discharge rate of less than $4.5 \mathrm{~m}^{3} / \mathrm{s}$, considering no socio-environmental and techno-economic exclusions (Table 1).

The head availability of the eligible streams was assessed in a $30 \mathrm{~m}$ ASTER DEM. We obtained the elevation of suitable streams on a $30 \mathrm{~m}$ interval and assign hydropower projects based on the analysis of river terrain from the elevation plot. A hydropower project should have a gross head not less than $20 \mathrm{~m}$. Due to hydraulic friction in the penstock, we estimated the net head by a $10 \%$ reduction in the gross head $[43,61]$. Also, allowing the river ecosystem to rejuvenate, we used a site spacing not less than $500 \mathrm{~m}$ [44]. We then estimated all developable hydro projects' capacity using the typical efficiency of $68.4 \%$ [43] in Eq. 9.

$\mathrm{PC}_{h, k}=\rho \times g \times \eta_{\mathrm{h}} \times Q_{e f f, k} \times \frac{h_{\text {net, }, k}}{10^{6}}$.

We applied the 2017 global weighted average capacity factor for hydropower at $48 \%$ [62] to estimate all developable hydro projects' energy yield using Eq. 10.

$E_{h, k}=\mathrm{CF}_{h, k} \times \mathrm{PC}_{h, k} \times T$.

\section{LCOE calculation and the supply curve}

A supply curve represents the cost and amount of energy in all modeled developable sites at a snapshot in time [57]. Analysis based on the supply curve is intended to provide policymakers and analysts with high-level indicative cost information about various RE resources, not the specific cost information about identified projects [63]. In this study, we used the simple proximity method to calculate each developable site's total LCOE taking into account the interconnection and access road construction costs. Supply curves were generated by plotting the sorted LCOEs against the cumulative capacity addition.

For each technology $m$, we calculated the total LCOE from the sum of the LCOE for generation (site-LCOE), interconnection, and road construction for each developable project $k$ (Eq. 11-14) [32]. Table 2 depicts the parameters used to estimate the total LCOE. Our estimates excluded the cost of operating and maintaining the spur line and the cost to maintain access road due to lack of data. They are, after all, only a small fraction of the respective capital costs. No adjustments are also needed for the cost parameters we used to obtain the LCOE (Table 2) because we used the 2030 projected cost from NREL's 2019 Annual Technology Baseline [64]. In the meantime, we calculated the energy-weighted LCOE to obtain a representative amount in which electricity consumers can be charged for the energy generation specified in a particular portfolio. Cost adjustment for integration, transmission, capacity value, and time-of-delivery [65] is beyond the scope of this study.

Site $-\mathrm{LCOE}_{m, k}=\frac{\left(I_{g e n, m}\right)(\mathrm{CRF})+O_{g e n, f i x, m}}{8760 \times \mathrm{CF}_{m, k}}+O_{g e n, v a r, m,}$

Interconnection $-\mathrm{LCOE}_{m, k}=\frac{\left(I_{\text {spur }, m}\right)\left(L_{\text {spur }, m, k}\right)(\mathrm{CRF})+\left(I_{s}\right)(\mathrm{CRF})}{8760 \times \mathrm{CF}_{m, k}}$

$\operatorname{Road}-\mathrm{LCOE}_{m, k}=\frac{I_{r d, m}\left(L_{r d, m, k}\right)(\mathrm{CRF})}{E_{m, k}}$ 
Table 2 Parameters used in estimating the total LCOE

\begin{tabular}{llllll}
\hline Parameters & Unit & Solar PV & Wind & Biopower & Hydropower \\
\hline Generation ${ }^{\text {a CapEx }}$ & 2019Php/MW & $56,707,554$ & $82,290,688$ & $212,226,080$ & $343,818,678$ \\
Fixed $^{\text {a GEN O\&M Expenses }}$ & 2019Php/MW-yr & 673,240 & $2,226,872$ & $5,800,225$ & $6,421,677$ \\
Variable $^{\text {a }}$ GEN O\&M Expenses & 2019Php/MWh & - & - & 2,434 & - \\
Spur $^{\text {b Line Capital Cost }}$ & 2019Php/MW-km & $23,304,474$ & $23,304,474$ & $23,304,474$ & $23,304,474$ \\
POI $^{\mathrm{b}}$ CapEx & 2019Php/MW & $3,625,140$ & $3,625,140$ & $3,625,140$ & $3,625,140$ \\
Road $^{\mathrm{c}}$ Construction Capital & Php/km & $21,890,338$ & $21,890,338$ & $21,890,338$ & $21,890,338$ \\
Plant lifespan & Years & 25 & 25 & 25 & 30 \\
WACC & $\%$ & 4.25 & 4.25 & 4.25 & 4.25 \\
\hline
\end{tabular}

a'Source: NREL's 2019 Annual Technology Baseline (ATB) [64]

${ }^{\mathrm{b}}$ Source: Deshmukh et al. [32]

${ }^{c}$ Roads leading to tourist destination (Central Visayas Region), Source: Philippines' Department of Public Works and Highways

$$
\mathrm{CRF}=\frac{i(1+i)^{N}}{\left((1+i)^{N}-1\right)}
$$

\section{Energy accounting}

Before analyzing the feasibility of any target RE share, the state of the province's energy supply and demand in the analysis horizon has to be evaluated first. In this case, we calculated the RE share of Bohol for the historical years 2009-2019 from the province's energy purchase data [3], Bohol's sub-grid energy generation [66], and the country's gross generation by plant type [2]. We then forecasted the province's and the country's energy mixes for 2020-2030 using regression analysis, econometric model, and imputed data. The province's RE shares computed for the year 2030 is regarded as the base RE share.

\section{A brief overview of the Philippine grid}

The Philippine electric grid is divided into three sub-grids: Luzon, Visayas, and Mindanao. The country's diversified energy portfolio comprises coal, natural gas, oil-based, and renewables (geothermal, hydro, biomass, solar, and wind). In 2019, coal-fired power plants generated more than half of the country's electricity supply at $54.6 \%$ (see Figs. 4 and 1) - the highest in the country's history.

Meanwhile, many technical factors and energy market conditions (i.e., availability, demand) influence energy production from any power facility. It is also bounded by the total dependable capacity and grid reliability requirements in different time frames. In the Philippines, coal-fired power plants usually serve baseload demand, but natural gas plants for mid-merit and oil-based plants for peaking. Geothermal plants also supply baseload, large hydro for midmerit, and the rest of the renewables enter the energy market

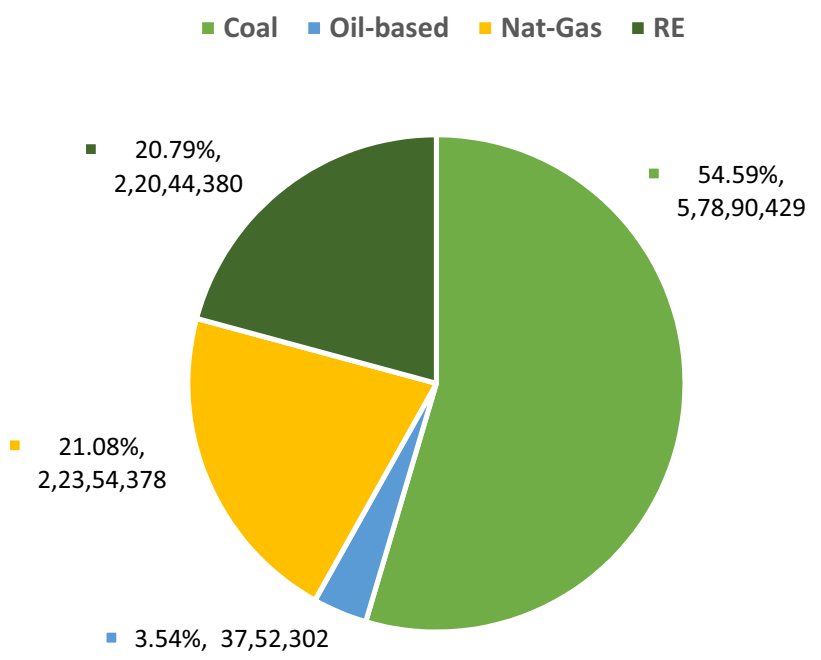

Fig. 42019 Philippine generation mix

following the priority dispatch protocol. This technicalmarket arrangement is vital in our forecast of the country's energy generation for each source type, and, subsequently, the country's future generation mix.

\section{Bohol historical domestic and imported generation}

The historical (2009-2015) and forecasted (2016-2019) energy purchase of the province derived from the aggregation of the results of the parametric trend analysis carried out by each DU on their annual metered energy purchase [3] was considered as the base energy demand. Since energy purchase is subject to losses from the energy generation perspective, we applied plant-to-meter (PTM) losses to calculate domestic contribution to the province's energy purchase (Table 3). We then estimated the province's annual energy import from the difference of the total energy purchase and the domestic energy contribution, assuming that 
Table 3 Energy losses, \% of the corresponding energy generation

\begin{tabular}{lll}
\hline Symbol & Description & $(\%)$ \\
\hline$\%$ SUTL & Percent system own-use and transmission loss & 8 \\
PTM $_{\text {re,ex }}$ & Plant-to-meter loss for existing embedded RE & 5 \\
PTM $_{\text {re,new }}$ & Plant-to-meter loss for new grid-connected RE & 6 \\
PTM $_{\text {nre }}$ & Plant-to-meter loss for existing grid-connected & 3 \\
& non-RE & \\
\hline
\end{tabular}

the corresponding RE and non-RE import percentage is proportional to the country's respective RE and non-RE generation (Eqs. 15-17). In this case, the energy import was adjusted for system own use and transmission loss of $8 \%$ to obtain the amount of energy generated outside Bohol for its demand (Table 3). RE penetration for Bohol is calculated using Eq. 18.

$$
\begin{aligned}
& \mathrm{RE}_{\text {import }}=\left(\% \mathrm{RE}_{\text {Phils }}\right)(1+\% \mathrm{SUTL})(\mathrm{EP}-\mathrm{DEC}) \\
& \mathrm{NONRE}_{\text {import }}=\left(\% \mathrm{NONRE}_{\text {Phils }}\right)(1+\% \mathrm{SUTL})(\mathrm{EP}-\mathrm{DEC}) \\
& \mathrm{DEC}=\mathrm{RE}_{\text {in,ex }}\left(1-\mathrm{PTM}_{\mathrm{re}, \mathrm{ex}}\right)+\mathrm{NRE}_{\text {in,ex }}\left(1-\mathrm{PTM}_{\mathrm{nre}}\right)
\end{aligned}
$$

Bohol\% $\mathrm{RE}=\frac{\mathrm{RE}_{\text {domestic }}+\mathrm{RE}_{\text {import }}}{\mathrm{E}_{\text {total }}}$.

Bohol's domestic energy generation is a combination of oil-based and renewables, as the province has a diesel-powered and three-embedded hydropower plants. Figure 5 shows that the share of renewables in the province is declined from $38.55 \%$ in 2009 to $22.74 \%$ in 2019 . No additional domestic RE capacity was constructed in the province since 2008 (when Sevilla mini-hydro started commercial operation), so its RE share depends on the country's declining RE penetration (see Fig. 1).

\section{Generation forecasts}

\section{Philippine generation mix}

Our forecast of the country's future generation mixes is primarily based on the assumption that coal-fired power plants supplied all residual generation. That is, we obtain its projected annual generation by taking the difference between the total projected energy generation and the sum of projected energy generated from REs, oil-based, and natural gas plants. Hence, we first forecasted the natural gas and oil-based generation, then the RE-based and total generation. We have 15 historical data in all (2005-2019), so we conducted serial correlation tests in three datasets: 15 year,

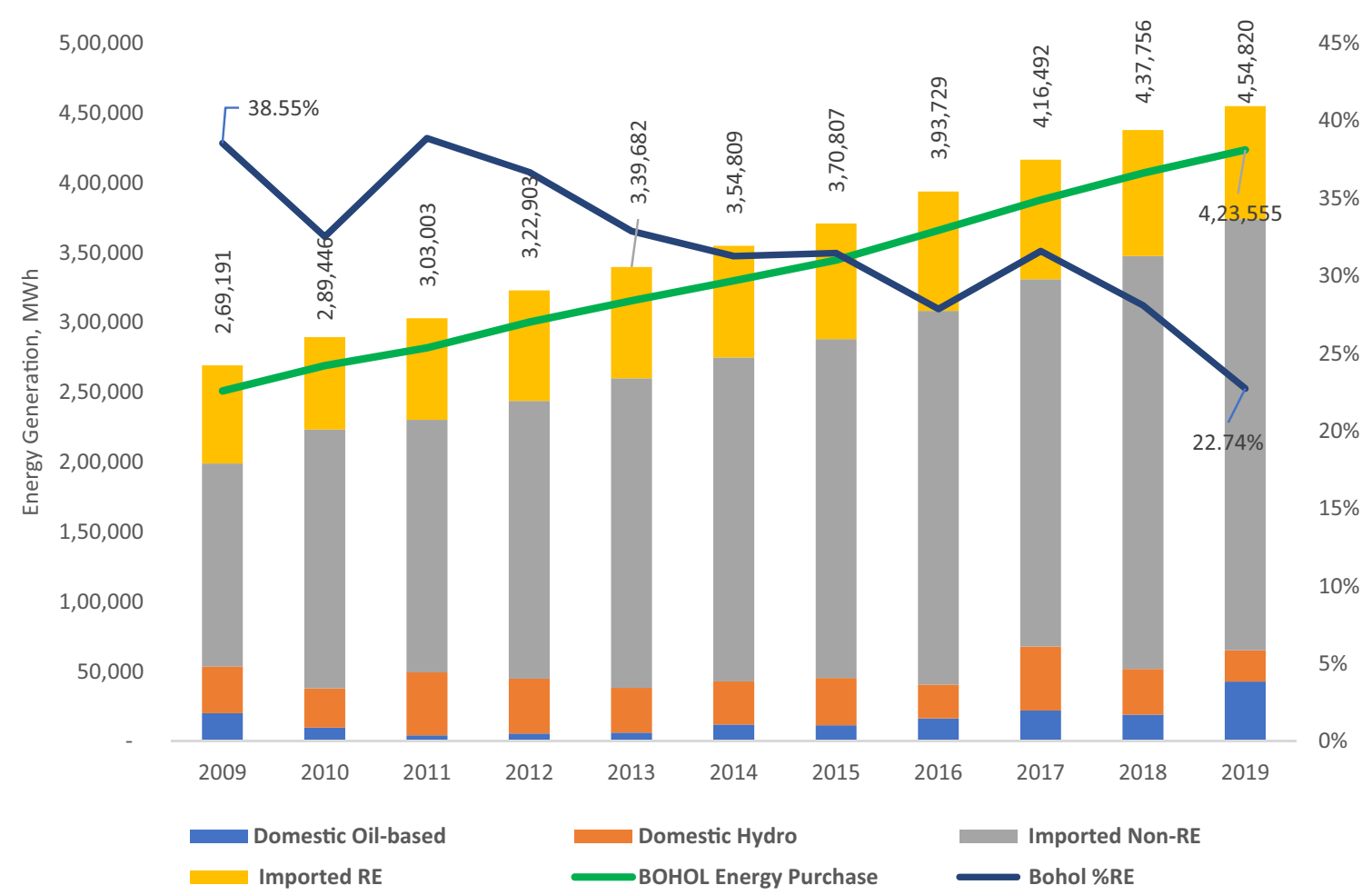

Fig. 5 Historical generation mix, RE share, and total energy purchase of Bohol province 
recent 10 year, and recent 7 year. Then, we choose the model that can be regarded as the best fit. In some instances, we preferred to use imputed data.

The correlation of the historical generation of oil-based power plants for all datasets considered is insignificant $(p>0.05)$, so we used imputed data (10-year average) for the country's projected oil-based energy generation. The correlation of the 7-year and 15-year historical generation for natural gas plants is significant $(p<0.05)$; however, we decided to use an imputed data (10-year average) due to the uncertainties brought by technical factors and market conditions. The retirement of natural gas plants by 2025 is also considered. The use of imputed data is plausible because our analysis of the Bohol RE portfolio is a snapshot of 2030 scenarios. For RE generation of the country, we have considered two scenarios: business-as-usual (BAU) and 35\% RE share (HRE). At a confidence level of 95\%, the correlation of the country's historical RE generation for all datasets considered is significant $(p<0.05)$. However, we choose the 7-year dataset for our RE-based generation forecast under the BAU scenario, because it resulted in higher energy estimates. Likewise, we obtained the forecasted RE generation for the $35 \%$ RE scenario by making assumptions of annual growth rate between 8 and 12\%. These assumptions imply a more rapid roll-out of new RE generation projects-doubling the energy generation by 2030 (see Fig. 6).

For the country's forecasted total energy generation, we used the econometric model of the Philippines' DOE in its 2016-2040 Power Development Plan [67]. We assumed the annual growth rate in gross domestic products (GDP) and elasticity (energy generation growth rate over GDP growth rate). The assumptions we made were comparable to those of Ref. [67]; however, we applied a lower but increasing GDP growth for 2020-2022 to consider the effect of coronavirus pandemic on the country's economy. COVID-19 pandemic has tremendously affected the Filipinos whose local livelihood and economic activities in the commercial and industrial sectors (including government offices) were temporarily closed at its onset. Progressive re-opening of the economy was seen after 6 months. However, the duration of the pandemic's new normal, which restricted many industries to operate fully, is still uncertain as of this writing.

The complete details of the energy mix calculation are available in the supplemental data [68]. We invite interested readers to visit https://dx.doi.org/10.17632/92xb8tnr9x.2 and look at the "Philippine Energy Mix" file. Meanwhile,

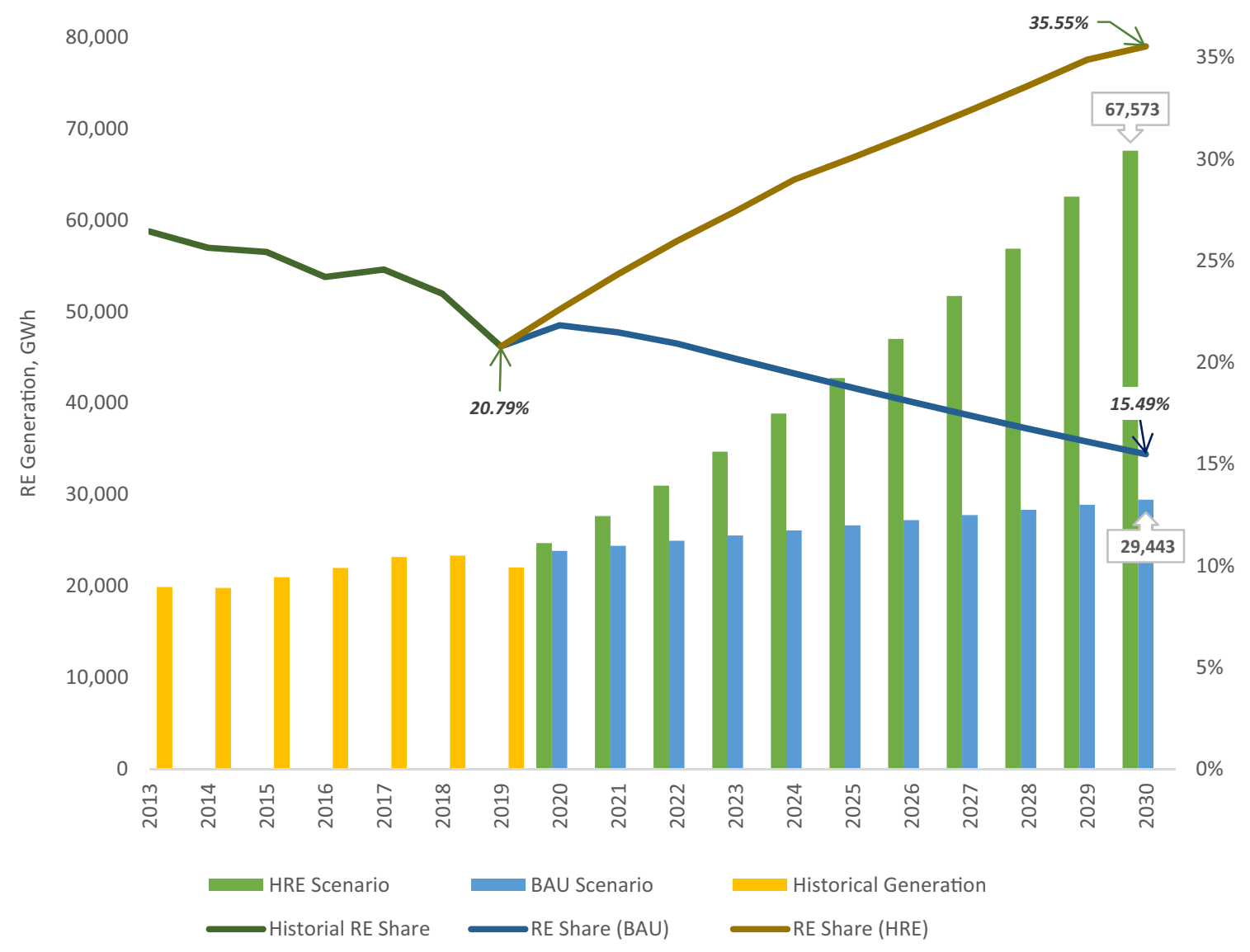

Fig. 6 Forecasted Philippines' RE generation and RE share for BAU and HRE scenarios 


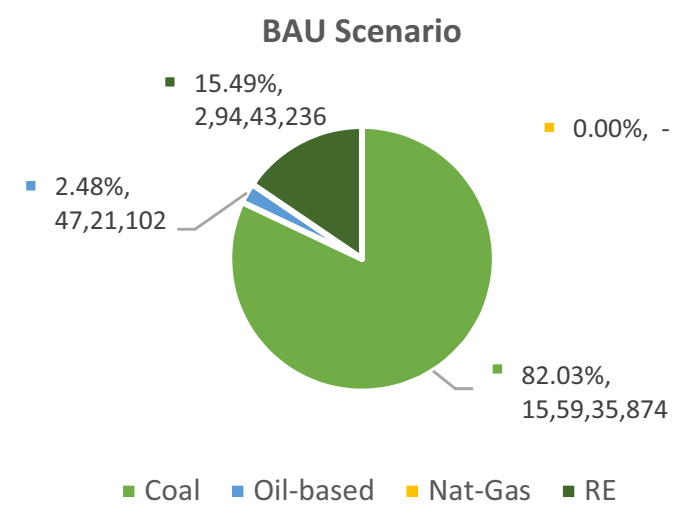

Fig. 72030 Philippine generation mix: BAU and HRE scenario

the results of this forecasting exercise revealed that, in any scenario, coal-fired power plants would contribute more than half of the country's energy generation by 2030 (see Fig. 7). In the absence of natural gas plants following the depletion of the Malampaya gas-to-power project by 2024, the energy generation share for coal-fired power plants can be as high as $82 \%$. The Philippines' DOE is eyeing for a cleaner substitute (liquified natural gas); however, reference data for its projected roll-out are not available.

\section{Domestic and imported generation}

With the country's generation mix and the forecast of Bohol's energy purchase, we can simply use the procedure outlined in the 'Bohol energy accounting' subsection to forecast the energy import for 2020 through 2030. However, we need to predict first the domestic generation so we could use Eqs. 15-17.

We conducted serial correlation tests to the historical (also 15-year) oil-based and hydropower generation data of Bohol. We found that, for all considered datasets, the correlation of the historical data for hydropower generation is insignificant $(p>0.05)$, so we used imputed data calculated based on the assumption of $42 \%$ capacity factor and the corresponding dependable capacities. Meanwhile, we cannot use regression analysis for the domestic oil-based generation due to technical reasons. The spike in the domestic oil-based energy generation in 2019 at 42,768 MWh (see Fig. 5 blue column) is primarily due to the energy supplied by the $32 \mathrm{MW}$ power barge in Ubay. Leyte-Bohol interconnection is expected to be overloaded this year, so an increase in this power barge's energy production is also anticipated. However, a $230 \mathrm{kv}, 200 \mathrm{MW}$ underwater cable linking Cebu and Bohol is also expected to come online by 2022. By 2023, the energy generation from the power barge can be minimal if not out of operation. Thus, for the year 2020-2022, we assumed Dampas and Ubay oilbased power plants to operate at $16 \%$ and $12 \%$ capacity factor, respectively. From 2023 to 2030, only Dampas oil-based plant
HRE Scenario

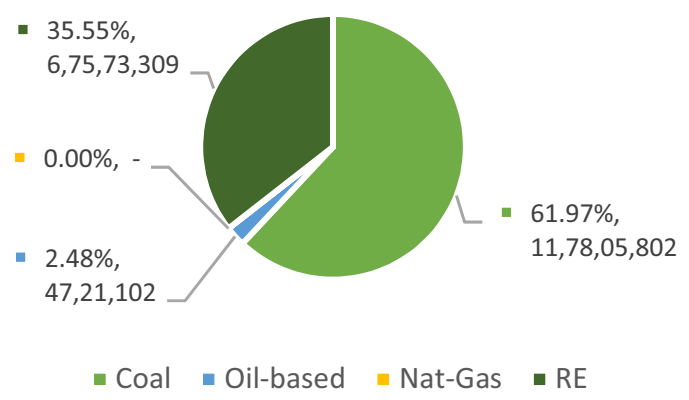

will be operating for peaking services. We have also considered the retirement of this facility by 2025 in our generation scenarios.

\section{Derivation of RE portfolio}

This section discusses how we derive the Bohol RE portfolio from the analysis of the supply curve and the domestic and imported energy generation. This task is not a capacity expansion modeling, which simulates the roll-out of the new generation over time, but a snapshot of the province's 2030 energy scenarios.

Using the supply curve, a renewable portfolio can be derived by selecting a set of RE projects capable of generating the amount of energy required for a particular \% RE target. The selection starts with the least-cost projects all the way up until cumulative energy generation is adequate. Estimation of energy import is now carried out using Eqs. 15,16, and 19, while RE penetration for the province is still calculated using Eq. 18. In this case, the share of RE is affected by three factors: (1) energy generation of the existing domestic facilities, (2) country's energy mix, and (3) the energy generation of additional RE facilities. The RE portfolio can come in various combinations, so we have to define scenarios according to these factors (see Table 4). First, we described generation scenarios to study the impact of the country's energy mix and the energy generation from existing domestic facilities. Second, considering the many different combinations in which an RE portfolio can be generated while investigating the effects of varying the power density, we also describe the capacity addition scenarios (Table 4). When we run 20 capacity addition scenarios in four generation scenarios, 80 portfolios were created and analyzed. Twenty supply curves were also produced and are available in the supplemental data [68]. The supply curve of all modeled RE projects is shown in Fig. 8 as a sample. 
Table 4 Description of scenarios

\begin{tabular}{|c|c|c|c|}
\hline Scenarios & \multicolumn{3}{|l|}{ Description/assumption } \\
\hline \multicolumn{4}{|l|}{ Generation } \\
\hline Business-As-Usual (BAU) & $\begin{array}{l}\text { Capacity factor of the three exist- } \\
\text { ing hydropower facility is } 42 \%\end{array}$ & $\begin{array}{l}\text { CF of the } 20 \text { MW Dampas } \\
\text { Diesel Power Plant is } 16 \% \text {. } \\
\text { CF of Power barge } 104 \text { is } 12 \% \\
(2020-2022)\end{array}$ & $\begin{array}{l}\text { Current trend of RE penetration in } \\
\text { the Philippines continues }\end{array}$ \\
\hline $\begin{array}{l}\text { Retire Diesel Power Plant (BAU- } \\
\text { RDPP) }\end{array}$ & $\begin{array}{l}\text { Capacity factor of the three exist- } \\
\text { ing hydropower facility is } 42 \%\end{array}$ & $\begin{array}{l}\text { Retire Dampas Diesel Power Plant } \\
\text { by } 2025\end{array}$ & $\begin{array}{l}\text { Current trend of RE penetration in } \\
\text { the Philippines continues }\end{array}$ \\
\hline $\begin{array}{l}\text { High RE in the Philippines } \\
\text { (HRE) }\end{array}$ & $\begin{array}{l}\text { Capacity factor of the three exist- } \\
\text { ing hydropower facility is } 42 \%\end{array}$ & $\begin{array}{l}\text { CF of the } 20 \text { MW Dampas } \\
\text { Diesel Power Plant is } 16 \% \text {. } \\
\text { CF of Power barge } 104 \text { is } 12 \% \\
(2020-2022)\end{array}$ & $\begin{array}{l}35 \% \text { RE share in the Philippines } \\
\text { by } 2030\end{array}$ \\
\hline $\begin{array}{l}\text { High RE-Retire Diesel Power } \\
\text { Plant (HRE-RDPP) }\end{array}$ & $\begin{array}{l}\text { Capacity factor of the three exist- } \\
\text { ing hydropower facility is } 42 \%\end{array}$ & $\begin{array}{l}\text { Retire Dampas Diesel Power Plant } \\
\text { by } 2025\end{array}$ & $\begin{array}{l}35 \% \text { RE share in the Philippines } \\
\text { by } 2030\end{array}$ \\
\hline \multicolumn{4}{|l|}{ RE capacity addition } \\
\hline Only Solar PV & \multicolumn{3}{|c|}{ RE portfolio is derived from solar PV developable projects only } \\
\hline Only Wind & \multicolumn{3}{|c|}{$\mathrm{RE}$ portfolio is derived from wind developable projects only } \\
\hline Only Bioenergy & \multicolumn{3}{|c|}{$\mathrm{RE}$ portfolio is derived from biomass developable projects only } \\
\hline Only Hydro & \multicolumn{3}{|c|}{ RE portfolio is derived from hydro developable projects only } \\
\hline VRE Only & \multicolumn{3}{|c|}{ RE portfolio is derived from solar PV and wind developable projects } \\
\hline SRE Only & \multicolumn{3}{|c|}{$\mathrm{RE}$ portfolio is derived from hydropower and bioenergy developable projects } \\
\hline Least-Cost (LC) & \multicolumn{3}{|c|}{$\mathrm{RE}$ portfolio is derived from all identified renewable projects } \\
\hline
\end{tabular}

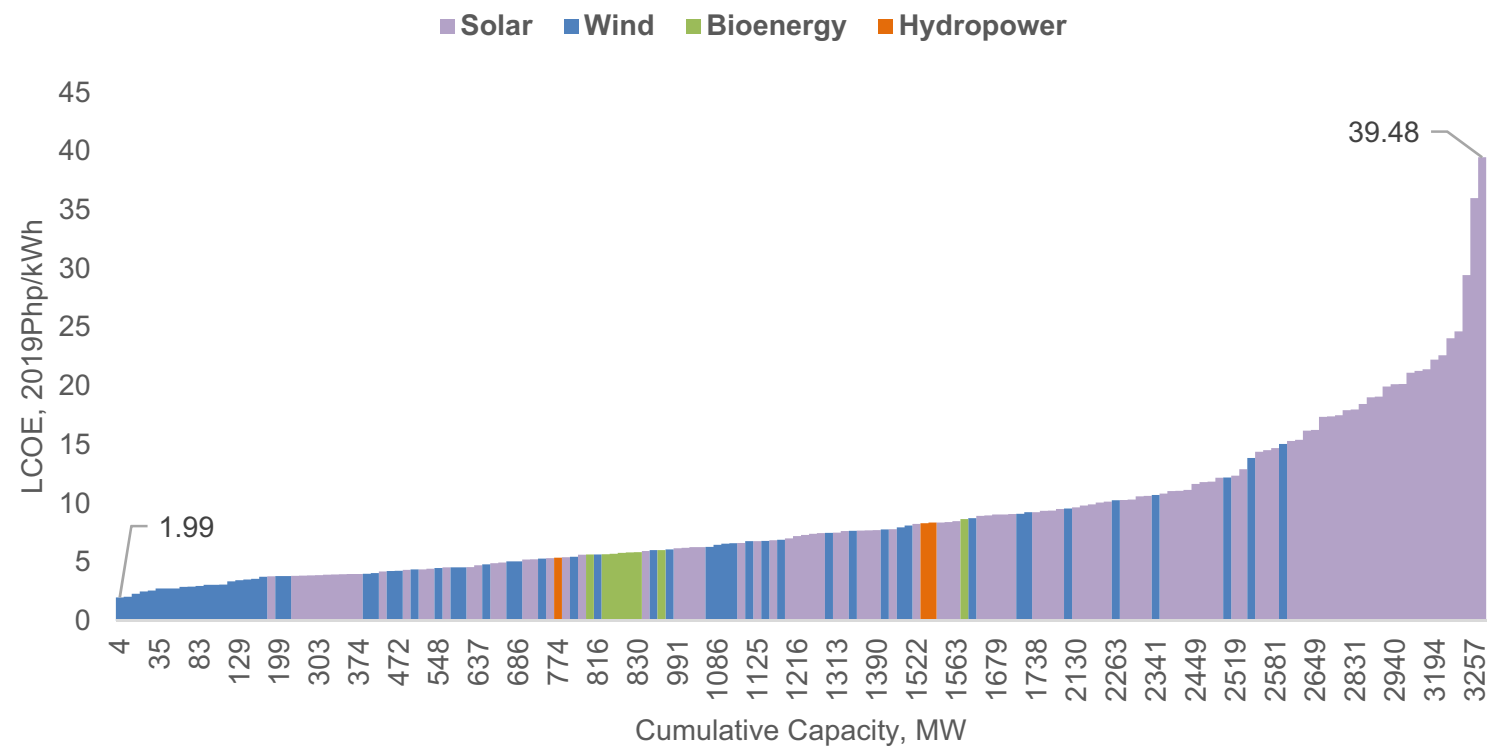

Fig. 8 Supply curve of all modeled developable sites. Capacity estimation assumptions: solar PV $100 \mathrm{MW} / \mathrm{km}^{2}$, wind $9 \mathrm{MW} / \mathrm{km}^{2}$, overall hydropower efficiency $68.4 \%$, biomass simulated in SAM

$$
\begin{aligned}
\mathrm{DEC}= & \mathrm{RE}_{\mathrm{in,ex}}\left(1-\mathrm{PTM}_{\mathrm{re}, \mathrm{ex}}\right)+\mathrm{RE}_{\mathrm{in, \text {new }}}\left(1-\mathrm{PTM}_{\mathrm{re}, \text { new }}\right) \\
& +\mathrm{NRE}_{\mathrm{in}, \mathrm{ex}}\left(1-\mathrm{PTM}_{\mathrm{nre}}\right) .
\end{aligned}
$$

We have also considered in our analysis a higher RE target at 50\%. Despite our methodology's technical and economic limitations in terms of system reliability and operation, storage, and curtailment, we have considered an ideal 100\% RE to understand the annual energy requirements for this theoretical setup and assess the province's feasibility to self-sustain energy production. 
We have also estimated the GHG emission reduction from the potential reduction in energy production from coal-fired power plants. We used the median lifecycle GHG emission found in the 2012 report of the Intergovernmental Panel on Climate Change [69]. First, we assumed that in every MWh of RE added, a MWh of coal-based generation is avoided. We then calculated the total reduction in carbon emission, considering the difference in the lifecycle emission of coalbased generation and the particular RE-based technology. That is, for a specific portfolio, the total carbon avoided (TCA) is given by

$\mathrm{TCA}=\sum\left(\mathrm{GHG}_{\text {coal }}-\mathrm{GHG}_{m}\right) \times E_{m}$, for allREtechnology $m$.

\section{Results and discussion}

\section{Upper-bound technical potential}

We found a total of 172 renewable projects in Bohol province (see Fig. 9). Based on our assumptions, the total capacity of these projects is between 391 and 3265 MW-capable of producing 999 to 5724 GWh annually (see Table 5 for complete details). Bohol's energy demand by 2030 is estimated at approximately $600 \mathrm{GWh}$ [3], so the province has enough technical potential to aspire for high RE penetration. $81 \%$ to 97\% of the energy generation may come from VRE projects, which can occupy up to $2.5 \%$ of the province's total land. Almost half the province can take part in biomass activity at $46.7 \%$.

\section{Bohol 2030 RE share: base case}

As a result of the procedure outlined in 'Energy accounting,' the historical and forecasted RE penetration for Bohol province is depicted in Fig. 10. Since the RE penetration presented in this graph is based on the assumption that no new generation facility is installed in the province, the 2030 RE share will be regarded as the "base case." The feasibility of increasing the province's RE penetration is evaluated by calculating the RE share when several new domestic RE generation facility is commercially operated before 2030 .

It appeared that Bohol's RE penetration is always higher than that of the country's - thanks to the three embedded

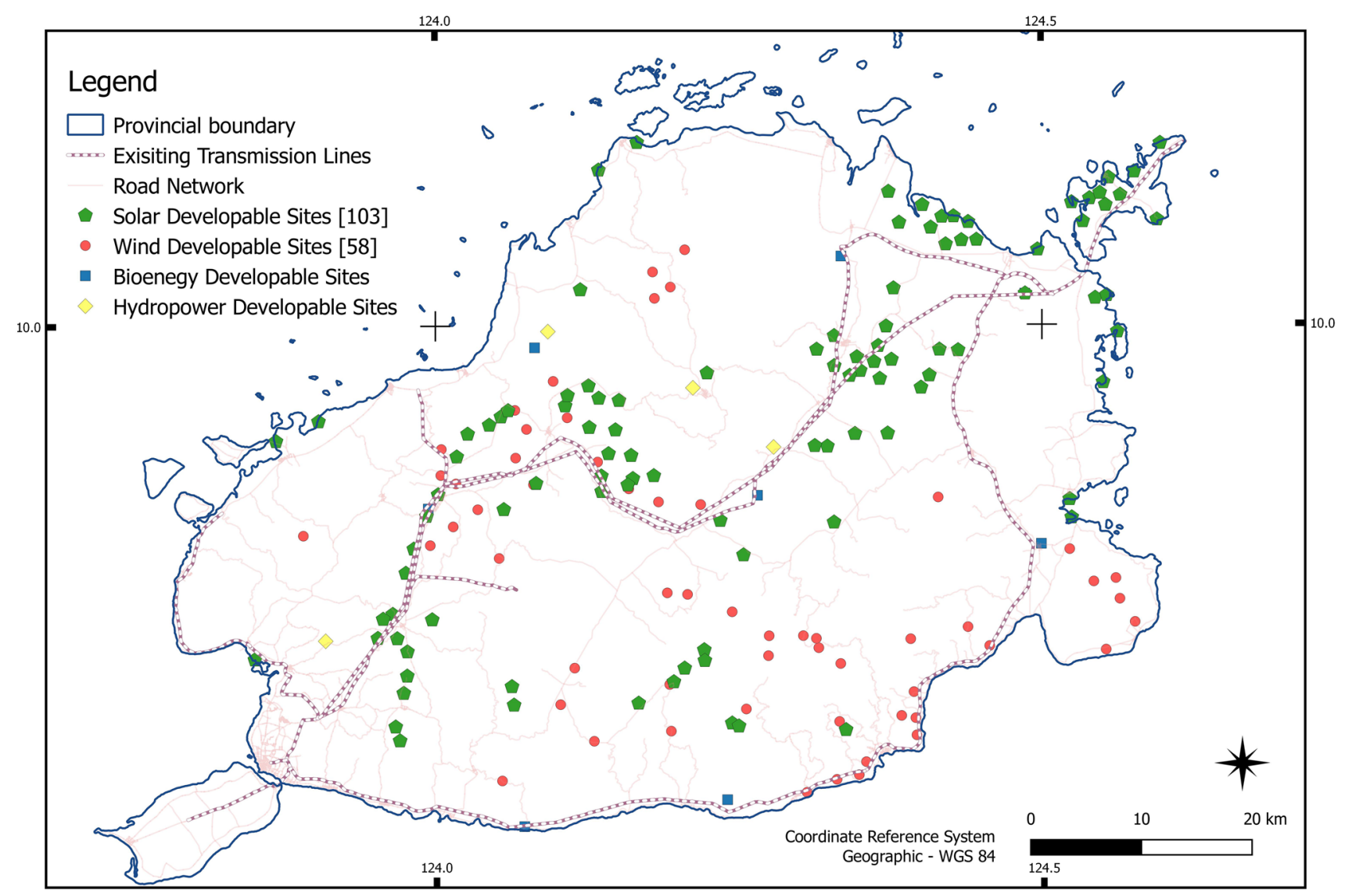

Fig. 9 Location of developable RE projects in Bohol, Philippines 
Table 5 The upper-bound technical potential of Bohol province

\begin{tabular}{|c|c|c|c|c|c|c|c|}
\hline \multirow[t]{2}{*}{$\begin{array}{l}\text { Renewable } \\
\text { technology }\end{array}$} & \multirow[t]{2}{*}{ Capacity estimation } & \multicolumn{3}{|c|}{$\begin{array}{l}\text { Developable Sites (DS) /Area of Biomass Activ- } \\
\text { ity (ABA) }\end{array}$} & \multirow[t]{2}{*}{$\begin{array}{l}\text { Total capac- } \\
\text { ity, MW }\end{array}$} & \multirow[t]{2}{*}{$\begin{array}{l}\text { Average capacity } \\
\text { factor, } \%\end{array}$} & \multirow{2}{*}{$\begin{array}{l}\text { Total energy } \\
\text { generation, } \\
\text { MWh }\end{array}$} \\
\hline & & \# of DS & Total area, $\mathrm{km}^{2}$ & $\begin{array}{l}\% \text { of Bohol } \\
\text { Area }(\%)\end{array}$ & & & \\
\hline \multirow[t]{3}{*}{ Solar } & $100 \mathrm{MW} / \mathrm{km}^{2}$ & 103 & 25.6 & 0.6 & 2562.6 & 14.6 & $3,277,412$ \\
\hline & $30 \mathrm{MW} / \mathrm{km}^{2}$ & 103 & 25.6 & 0.6 & 768.8 & 14.6 & 983,224 \\
\hline & $7.5 \mathrm{MW} / \mathrm{km}^{2}$ & 103 & 25.6 & 0.6 & 192.2 & 14.6 & 245,806 \\
\hline \multirow[t]{2}{*}{ Wind } & $9 \mathrm{MW} / \mathrm{km}^{2}$ & 58 & 74.6 & $1.9 \%$ & 671.7 & 39.2 & $2,257,177$ \\
\hline & $2.25 \mathrm{MW} / \mathrm{km}^{2}$ & 58 & 74.6 & 1.9 & 167.9 & 39.2 & 564,294 \\
\hline Biopower & Using SAM & 8 & 1856 & 46.7 & 21.8 & 72.3 & 138,282 \\
\hline Hydro & $\mathrm{Eff}=68.4 \%$ & 3 & - & - & 9.3 & 62.0 & 50,617 \\
\hline
\end{tabular}

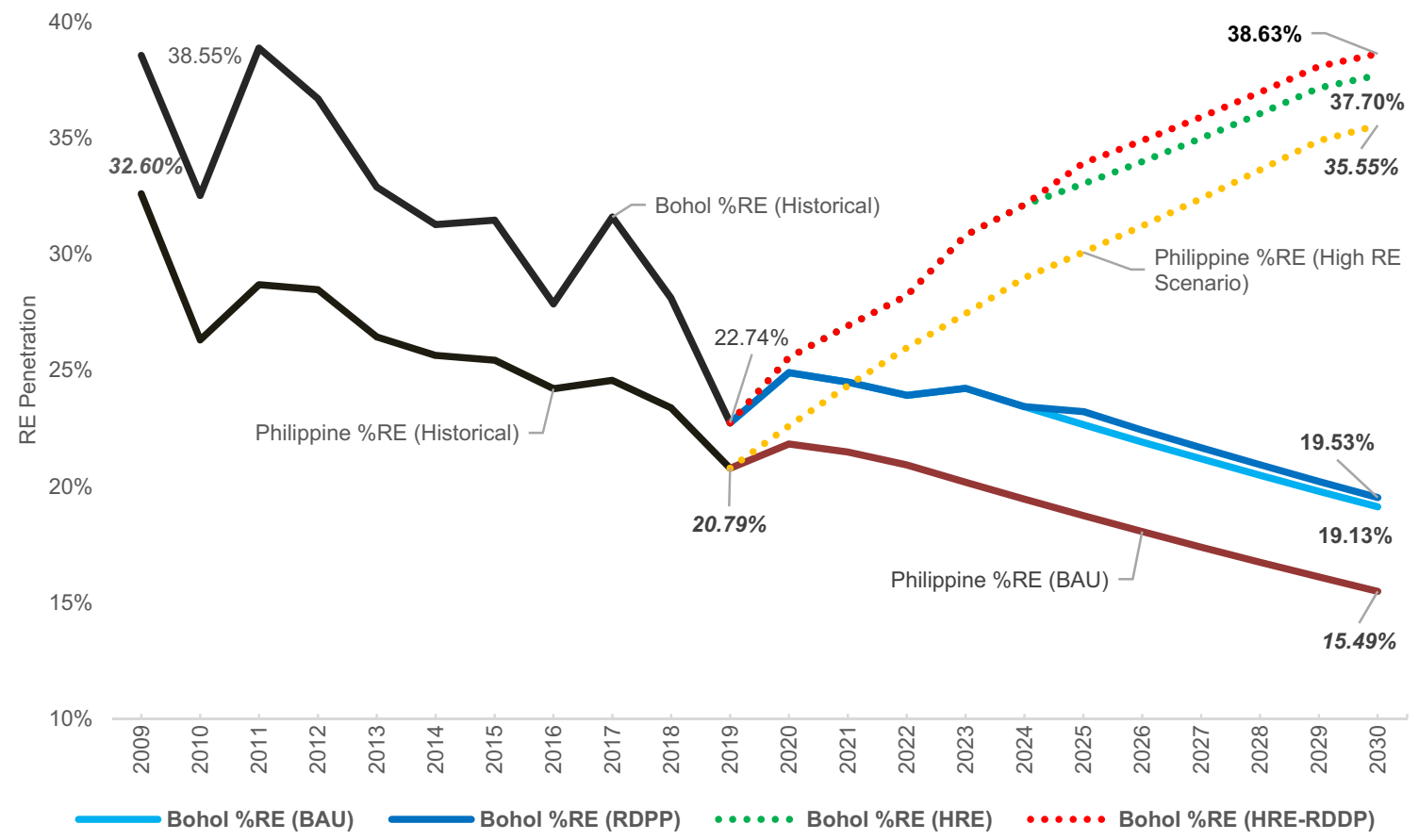

Fig. 10 Base cases of Bohol's RE penetration (bold) versus Philippines' RE penetration (bold italic)

hydropower plants which have always supplied energy at a domestically higher percentage than the country's \%RE share. If the current trend of the country's RE penetration continues and the Dampas oil-based generation facility continues to operate, Bohol's base RE share is at its lowest (19.13\%). However, when this oil-based facility is retired, the province's base RE share can be as low as $19.53 \%$. Meanwhile, when the country's RE share approaches $35 \%$ with new generation facilities deployed in other provinces, Bohol's base RE share can be $37.7 \% \%$ with the existing oil-based power plant in service, $38.63 \%$ on its retirement. In this case, Bohol can aspire for high RE targets such as $50 \%$ share or even higher utilizing its domestic resources.

\section{Additional domestic RE generation vis-a-vis Bohol's RE penetration}

In this section, we explain how new domestic RE generation affects the RE share of Bohol. Let us take a scenario where only solar PV is considered for the new generation under business-as-usual. At this scenario, the province's base RE share is approximately $19.13 \%$ (see Fig. 10). In this case, some $610 \mathrm{MWh}$ of energy needs to be generated for Bohol's 2030 demand considering losses in transmission and distribution (Table 6). When the first five leastcost projects (95 MW cumulative capacity) in the supply 


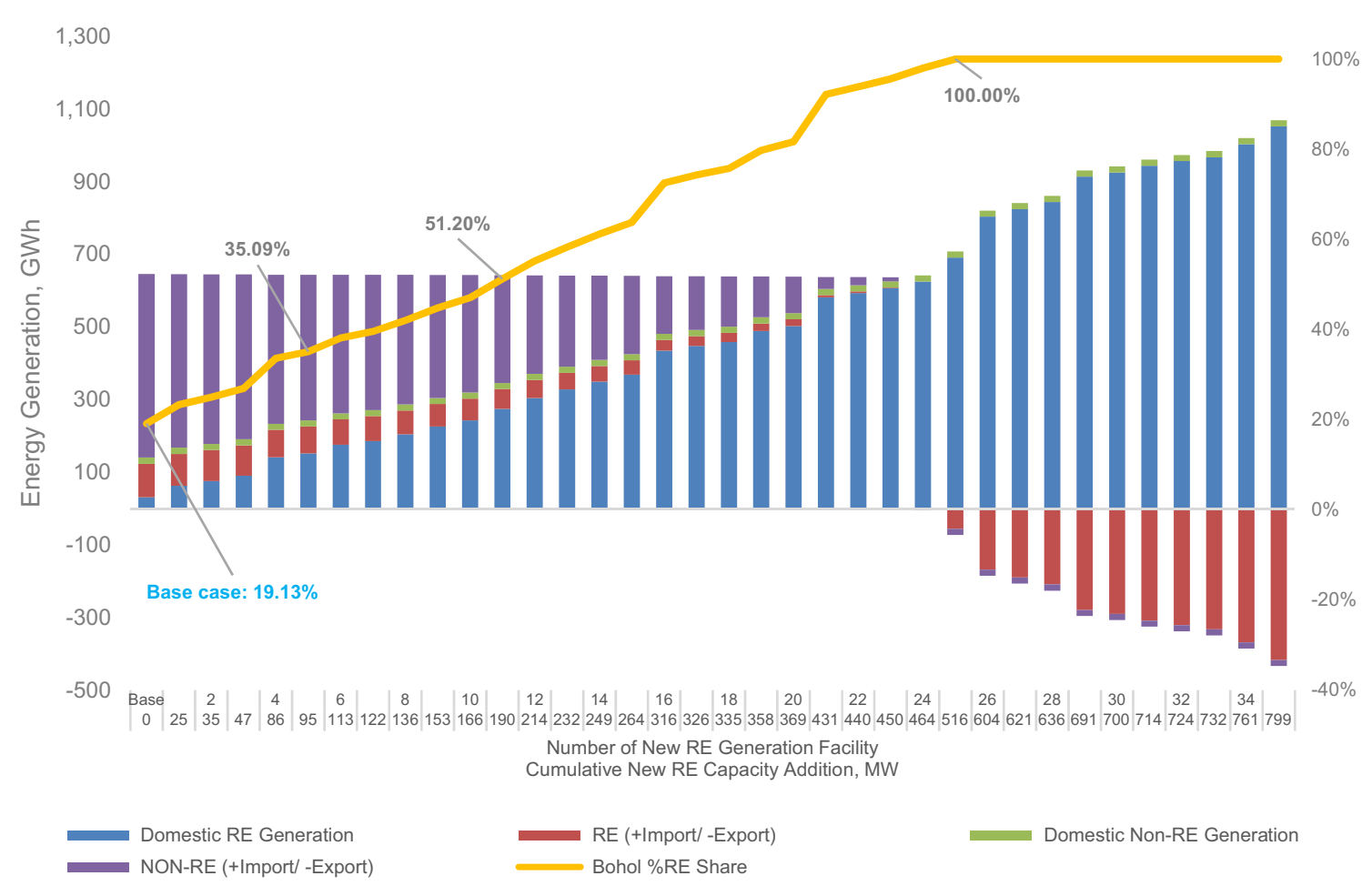

Fig. 11 Bohol's 2030 energy generation mix plotted against its RE share (generation scenario: BAU, new generation added: all solar PV, power density: $100 \mathrm{MW} / \mathrm{km}^{2}$ )

Table 6 Approximate annual domestic new RE generation for a target RE share

\begin{tabular}{lllll}
\hline Generation scenario & Base case (\%) & \multicolumn{2}{l}{ RE Generation, GWh } \\
\cline { 3 - 5 } & & $35 \%$ RE target & $50 \%$ RE target & $\begin{array}{l}\text { Max } \\
\% \text { RE } \\
\text { target }\end{array}$ \\
\hline BAU & & & 235 & 609 \\
BAU-RDPP & 19.13 & 121 & 232 & 607 \\
HRE & 19.53 & 118 & 123 & 615 \\
HRE-RDPP & 37.70 & - & 114 & 607 \\
\hline
\end{tabular}

The reference demand is the total annual energy purchase of the three DUs. So, the target energy generation is anticipated to be higher than the 2030 base demand $(600 \mathrm{GWh})$ due to losses in transmission and distribution. However, these values are computed from Eq. 18 on the assumption of the exact values of RE share. Thus, the total generation of any portfolio is always higher than the values in this table curve are considered, the RE share can be $35.09 \%$ (see Fig. 11). When the next six projects (now $190 \mathrm{MW}$ cumulative capacity), the $50 \%$ RE target can be achieved. When 11 more projects were connected, the province started to export a fraction of the domestic RE generation to the neighboring island. Subsequently, the theoretical $100 \%$ RE can potentially be reached considering a total of at least 25 solar PV projects. In this case, all domestic non-RE and excess RE generation are exported to the neighboring island.

\section{Bohol's RE portfolio}

\section{BAU}

Between now and 2030, domestic RE facilities capable of generating at least $121 \mathrm{GWh}$ per year are required to raise the province's RE share from $19.13 \%$ to $35 \%$. Higher targets such as $50 \%$ are achievable with a cumulative addition of $235 \mathrm{GWh}$, while the theoretical $100 \%$ RE can be attained with at least $609 \mathrm{GWh}$ (see Table 6). The breakdown of capacity addition and the corresponding energy generation are respectively shown in Tables 7 and 8. It appeared that the province is capable of achieving the $35 \%$ target in all 
Table 7 Cumulative capacity addition for Bohol province under BAU generation scenario, MW

\begin{tabular}{|c|c|c|c|c|c|c|c|c|c|c|c|c|c|}
\hline \multirow[t]{2}{*}{ Capacity addition scenario } & \multicolumn{4}{|c|}{$35 \% \mathrm{RE}$} & \multicolumn{4}{|c|}{$50 \% \mathrm{RE}$} & \multirow{2}{*}{$\begin{array}{l}\text { Max \%RE } \\
\text { Share (\%) }\end{array}$} & \multicolumn{4}{|c|}{ Max \%RE } \\
\hline & Solar & Wind & Bio & Hydro & Solar & Wind & Bio & Hydro & & Solar & Wind & Bio & Hydro \\
\hline Only Solar PV (100 MW/km²) & 95.0 & - & - & - & 190.5 & - & - & - & 100 & 516.3 & - & - & - \\
\hline Only Solar PV (30 MW/km²) & 94.8 & - & - & - & 181.3 & - & - & - & 100 & 478.0 & - & - & - \\
\hline Only Solar PV (7.5 MW/km²) & 96.2 & - & - & - & 186.1 & - & - & - & 51 & 192.2 & - & - & - \\
\hline Only Wind $\left(9 \mathrm{MW} / \mathrm{km}^{2}\right)$ & - & 34.5 & - & - & - & 71.9 & - & - & 100 & - & 208.1 & - & - \\
\hline Only Wind (2.25 MW/km²) & - & 37.7 & - & - & - & 73.5 & - & - & 94 & - & 167.9 & - & - \\
\hline Only Biomass & - & - & 20.2 & - & - & - & - & - & 37 & - & - & 21.8 & - \\
\hline Only Hydro & - & - & - & - & - & - & - & - & 26 & - & - & - & 9.3 \\
\hline VRE-1 & - & 34.5 & - & - & - & 71.9 & - & - & 100 & 25.0 & 208.1 & - & - \\
\hline VRE-2 & - & 37.7 & - & - & 86.5 & 47.1 & - & - & 100 & 315.8 & 73.5 & - & - \\
\hline VRE-3 & - & 34.5 & - & - & - & 71.9 & - & - & 100 & - & 208.1 & - & - \\
\hline VRE-4 & - & 37.7 & - & - & 41.8 & 55.1 & - & - & 100 & 207.2 & 103.3 & - & - \\
\hline VRE-5 & - & 34.5 & - & - & - & 71.9 & - & - & 100 & - & 208.1 & - & - \\
\hline VRE-6 & - & 37.7 & - & - & 4.1 & 69.2 & - & - & 100 & 89.3 & 147.2 & - & - \\
\hline Seasonal RE Only & - & - & 20.2 & 1.2 & - & - & - & - & 44 & - & - & 21.8 & 9.3 \\
\hline LC-1 & - & 34.5 & - & - & - & 71.9 & - & - & 100 & 25.0 & 208.1 & - & - \\
\hline LC-2 & - & 37.7 & - & - & 86.5 & 47.1 & - & - & 100 & 315.8 & 73.5 & - & - \\
\hline LC-3 & - & 34.5 & - & - & - & 71.9 & - & - & 100 & - & 208.1 & - & - \\
\hline LC-4 & - & 37.7 & - & - & 41.8 & 55.1 & - & - & 100 & 154.9 & 86.9 & 20.2 & 1.2 \\
\hline LC-5 & - & 34.5 & - & - & - & 71.9 & - & - & 100 & - & 208.1 & - & - \\
\hline LC-6 & - & 37.7 & - & - & 4.1 & 69.2 & - & - & 100 & 56.5 & 131.4 & 20.2 & 1.2 \\
\hline
\end{tabular}

Bold values indicate the scenarios where the $100 \%$ target is achieved

Table 8 Cumulative energy generation for Bohol RE capacity addition under BAU generation scenario, GWh

\begin{tabular}{|c|c|c|c|c|c|c|c|c|c|c|c|c|c|}
\hline \multirow[t]{2}{*}{ Capacity addition scenario } & \multicolumn{4}{|c|}{$35 \% \mathrm{RE}$} & \multicolumn{4}{|c|}{$50 \% \mathrm{RE}$} & \multirow{2}{*}{$\begin{array}{l}\text { Max \%RE } \\
\text { Share (\%) }\end{array}$} & \multicolumn{4}{|c|}{ Max \%RE } \\
\hline & Solar & Wind & Bio & Hydro & Solar & Wind & Bio & Hydro & & Solar & Wind & Bio & Hydro \\
\hline Only Solar PV (100 MW/km²) & 122 & - & - & - & 244 & - & - & - & 100 & 660 & - & - & - \\
\hline Only Solar PV (30 MW/km²) & 121 & - & - & - & 232 & - & - & - & 100 & 611 & - & - & - \\
\hline Only Solar PV (7.5 MW/km²) & 123 & - & - & - & 238 & - & - & - & 51 & 246 & - & - & - \\
\hline Only Wind $\left(9 \mathrm{MW} / \mathrm{km}^{2}\right)$ & - & 129 & - & - & - & 247 & - & - & 100 & - & 709 & - & - \\
\hline Only Wind (2.25 MW/km²) & - & 122 & - & - & - & 242 & - & - & 94 & - & 564 & - & - \\
\hline Only Biomass & - & - & 128 & - & - & - & - & - & 37 & - & - & 138 & - \\
\hline Only Hydro & - & - & - & - & - & - & - & - & 26 & - & - & - & 51 \\
\hline VRE-1 & - & 129 & - & - & - & 247 & - & - & 100 & 32 & 709 & - & - \\
\hline VRE-2 & - & 122 & - & - & 111 & 162 & - & - & 100 & 404 & 242 & - & - \\
\hline VRE-3 & - & 129 & - & - & - & 247 & - & - & 100 & - & 709 & - & - \\
\hline VRE-4 & - & 122 & - & - & 53 & 186 & - & - & 100 & 265 & 353 & - & - \\
\hline VRE-5 & - & 129 & - & - & - & 247 & - & - & 100 & - & 709 & - & - \\
\hline VRE-6 & - & 122 & - & - & 5 & 230 & - & - & 100 & 114 & 503 & - & - \\
\hline Seasonal RE Only & - & - & 128 & 7 & - & - & - & - & 44 & - & - & 138 & 51 \\
\hline LC-1 & - & 129 & - & - & - & 247 & - & - & 100 & 32 & 709 & - & - \\
\hline LC-2 & - & 122 & - & - & 111 & 162 & - & - & 100 & 404 & 242 & - & - \\
\hline LC-3 & - & 129 & - & - & - & 247 & - & - & 100 & - & 709 & - & - \\
\hline LC-4 & - & 122 & - & - & 53 & 186 & - & - & 100 & 198 & 290 & 128 & 7 \\
\hline LC-5 & - & 129 & - & - & - & 247 & - & - & 100 & - & 709 & - & - \\
\hline LC-6 & - & 122 & - & - & 5 & 230 & - & - & 100 & 72 & 451 & 128 & 7 \\
\hline
\end{tabular}

Bold values indicate the scenarios where the $100 \%$ target is achieved 
capacity addition scenarios, except when only hydro is considered (26\% share only), and the 50\% RE is achievable if VRE technologies are included in the portfolio. SRE technologies are also insufficient for this target. The theoretical $100 \%$ RE share is also possible in all scenarios with VRE technologies on the assumption of higher power density.

\section{BAU-RDPP}

When the oil-based grid-connected power plant is retired, and the trend of RE penetration in the country continues, Bohol's base RE share is estimated to be approximately $19.53 \%$ (see Table 6). RE projects capable of generating $118 \mathrm{GWh}$ per year are essential to raise the RE share to $35 \%$ in all capacity addition scenarios, but the only hydro (only $26 \%$ ). A higher RE target share of $50 \%$, which requires a minimum annual energy generation of $232 \mathrm{GWh}$, is also attainable in all scenarios with VRE technologies included in the portfolio. SRE technologies are not enough to meet this target (maximum 44\%). The theoretical 100\% RE, which requires the addition of at least $607 \mathrm{GWh}$ annual energy generation, is also achievable in all scenarios with VRE technologies on high assumptions of power densities. Please see Tables 9 and 10 for complete details.
HRE

When the domestic generation continues and the country's RE penetration approaches 35\% due to additional RE capacity outside Bohol, Bohol's base RE share was estimated at $37.7 \%$. It implies that the domestic RE potential can aspire for higher RE targets such as 50\%. In such a case, an annual generation of $123 \mathrm{GWh}$ is needed (see Table 6). The results shown in Tables 11 and 12 indicated that it is attainable under any capacity addition scenarios except when only hydro is considered (only 43\%). The theoretical 100\% RE share, which requires approximately $615 \mathrm{GWh}$ of new RE generation, is also possible in all scenarios with the VRE technologies under higher power density assumptions.

\section{HRE-RDPP}

When the oil-based grid-connected domestic power plant is retired, and the country's RE penetration reaches 35\%, Bohol's base RE share was estimated at $38.63 \%$. A higher $50 \% \mathrm{RE}$ target requiring $114 \mathrm{GWh}$ of additional domestic $\mathrm{RE}$ generation is possible under all capacity addition scenarios (see Tables 13 and 14) except only hydro (44\%). The theoretical $100 \%$ RE share can also be achieved so long as VRE technologies are included in the RE portfolio.

Table 9 Cumulative capacity addition for Bohol province under the BAU-RDPP generation scenario, MW

\begin{tabular}{|c|c|c|c|c|c|c|c|c|c|c|c|c|c|}
\hline \multirow[t]{2}{*}{ Capacity addition scenario } & \multicolumn{4}{|c|}{$35 \% \mathrm{RE}$} & \multicolumn{4}{|c|}{$50 \% \mathrm{RE}$} & \multirow{2}{*}{$\begin{array}{l}\text { Max \%RE } \\
\text { Share (\%) }\end{array}$} & \multicolumn{4}{|c|}{ Max \%RE } \\
\hline & Solar & Wind & Bio & Hydro & Solar & Wind & Bio & Hydro & & Solar & Wind & Bio & Hydro \\
\hline Only Solar PV (100 MW/km²) & 95.0 & - & - & - & 190.5 & - & - & - & 100 & 516.3 & - & - & - \\
\hline Only Solar PV (30 MW/km²) & 94.8 & - & - & - & 181.3 & - & - & - & 100 & 478.0 & - & - & - \\
\hline Only Solar PV (7.5 MW/km²) & 92.9 & - & - & - & 181.3 & - & - & - & 52 & 192.2 & - & - & - \\
\hline Only Wind $\left(9 \mathrm{MW} / \mathrm{km}^{2}\right)$ & - & 34.5 & - & - & - & 71.9 & - & - & 100 & - & 208.1 & - & - \\
\hline Only Wind (2.25 MW/km²) & - & 37.7 & - & - & - & 70.3 & - & - & 94 & - & 167.9 & - & - \\
\hline Only Biomass & - & - & 20.2 & - & - & - & - & - & 38 & - & - & 21.8 & - \\
\hline Only Hydro & - & - & - & - & - & - & - & - & 26 & - & - & - & 9.3 \\
\hline VRE-1 & - & 34.5 & - & - & - & 71.9 & - & - & 100 & 25.0 & 208.1 & - & - \\
\hline VRE-2 & - & 37.7 & - & - & 86.5 & 47.1 & - & - & 100 & 315.8 & 73.5 & - & - \\
\hline VRE-3 & - & 34.5 & - & - & - & 71.9 & - & - & 100 & - & 208.1 & - & - \\
\hline VRE-4 & - & 37.7 & - & - & 41.8 & 55.1 & - & - & 100 & 207.2 & 100.9 & - & - \\
\hline VRE-5 & - & 34.5 & - & - & - & 71.9 & - & - & 100 & - & 208.1 & - & - \\
\hline VRE-6 & - & 37.7 & - & - & 3.0 & 69.2 & - & - & 100 & 89.3 & 147.2 & - & - \\
\hline Seasonal RE Only & - & - & 20.2 & 1.2 & - & - & - & - & 44 & - & - & 21.8 & 9.3 \\
\hline LC-1 & - & 34.5 & - & - & - & 71.9 & - & - & 100 & 25.0 & 208.1 & - & - \\
\hline LC-2 & - & 37.7 & - & - & 86.5 & 47.1 & - & - & 100 & 315.8 & 73.5 & - & - \\
\hline LC-3 & - & 34.5 & - & - & - & 71.9 & - & - & 100 & - & 208.1 & - & - \\
\hline LC-4 & - & 37.7 & - & - & 41.8 & 55.1 & - & - & 100 & 154.9 & 86.9 & 20.2 & 1.2 \\
\hline LC-5 & - & 34.5 & - & - & - & 71.9 & - & - & 100 & - & 208.1 & - & - \\
\hline LC-6 & - & 37.7 & - & - & 3.0 & 69.2 & - & - & 100 & 56.5 & 131.4 & 20.2 & 1.2 \\
\hline
\end{tabular}

Bold values indicate the scenarios where the $100 \%$ target is achieved 
Table 10 Cumulative energy generation for Bohol RE capacity addition under the BAU-RDPP generation scenario, GWh

\begin{tabular}{|c|c|c|c|c|c|c|c|c|c|c|c|c|c|}
\hline \multirow[t]{2}{*}{ Capacity addition scenario } & \multicolumn{4}{|c|}{$35 \% \mathrm{RE}$} & \multicolumn{4}{|c|}{$50 \% \mathrm{RE}$} & \multirow{2}{*}{$\begin{array}{l}\text { Max \%RE } \\
\text { Share (\%) }\end{array}$} & \multicolumn{4}{|c|}{ Max \%RE } \\
\hline & Solar & Wind & Bio & Hydro & Solar & Wind & Bio & Hydro & & Solar & Wind & Bio & Hydro \\
\hline Only Solar PV (100 MW/km²) & 122 & - & - & - & 244 & - & - & - & 100 & 660 & - & - & - \\
\hline Only Solar PV (30 MW/km²) & 121 & - & - & - & 232 & - & - & - & 100 & 611 & - & - & - \\
\hline Only Solar PV (7.5 MW/ $\left.\mathrm{km}^{2}\right)$ & 119 & - & - & - & 232 & - & - & - & 52 & 246 & - & - & - \\
\hline Only Wind $\left(9 \mathrm{MW} / \mathrm{km}^{2}\right)$ & - & 129 & - & - & - & 247 & - & - & 100 & - & 709 & - & - \\
\hline Only Wind (2.25 MW/km²) & - & 122 & - & - & - & 233 & - & - & 94 & - & 564 & - & - \\
\hline Only Biomass & - & - & 128 & - & - & - & - & - & 38 & - & - & 138 & - \\
\hline Only Hydro & - & - & - & - & - & - & - & - & 26 & - & - & - & 51 \\
\hline VRE-1 & - & 129 & - & - & - & 247 & - & - & 100 & 32 & 709 & - & - \\
\hline VRE-2 & - & 122 & - & - & 111 & 162 & - & - & 100 & 404 & 242 & - & - \\
\hline VRE-3 & - & 129 & - & - & - & 247 & - & - & 100 & - & 709 & - & - \\
\hline VRE-4 & - & 122 & - & - & 53 & 186 & - & - & 100 & 265 & 343 & - & - \\
\hline VRE-5 & - & 129 & - & - & - & 247 & - & - & 100 & - & 709 & - & - \\
\hline VRE-6 & - & 122 & - & - & 4 & 230 & - & - & 100 & 114 & 503 & - & - \\
\hline Seasonal RE Only & - & - & 128 & 7 & - & - & - & - & 44 & - & - & 138 & 51 \\
\hline LC-1 & - & 129 & - & - & - & 247 & - & - & 100 & 32 & 709 & - & - \\
\hline LC-2 & - & 122 & - & - & 111 & 162 & - & - & 100 & 404 & 242 & - & - \\
\hline LC-3 & - & 129 & - & - & - & 247 & - & - & 100 & - & 709 & - & - \\
\hline LC-4 & - & 122 & - & - & 53 & 186 & - & - & 100 & 198 & 290 & 128 & 7 \\
\hline LC-5 & - & 129 & - & - & - & 247 & - & - & 100 & - & 709 & - & - \\
\hline LC-6 & - & 122 & - & - & 4 & 230 & - & - & 100 & 72 & 451 & 128 & 7 \\
\hline
\end{tabular}

Bold values indicate the scenarios where the $100 \%$ target is achieved

Table 11 Cumulative capacity addition for Bohol province under HRE generation scenario, MW

\begin{tabular}{|c|c|c|c|c|c|c|c|c|c|c|c|c|c|}
\hline \multirow[t]{2}{*}{ Capacity addition scenario } & \multicolumn{4}{|c|}{$35 \% \mathrm{RE}$} & \multicolumn{4}{|c|}{$50 \% \mathrm{RE}$} & \multirow{2}{*}{$\begin{array}{l}\text { Max \%RE } \\
\text { Share (\%) }\end{array}$} & \multicolumn{4}{|c|}{ Max \%RE } \\
\hline & Solar & Wind & Bio & Hydro & Solar & Wind & Bio & Hydro & & Solar & Wind & Bio & Hydro \\
\hline Only Solar PV (100 MW/km²) & - & - & - & - & 113.2 & - & - & - & 100 & 516.3 & - & - & - \\
\hline Only Solar PV (30 MW/km²) & - & - & - & - & 97.8 & - & - & - & 100 & 492.5 & - & - & - \\
\hline Only Solar PV (7.5 MW/km²) & - & - & - & - & 96.2 & - & - & - & 62 & 192.2 & - & - & - \\
\hline Only Wind $\left(9 \mathrm{MW} / \mathrm{km}^{2}\right)$ & - & - & - & - & - & 34.5 & - & - & 100 & - & 208.1 & - & - \\
\hline Only Wind $\left(2.25 \mathrm{MW} / \mathrm{km}^{2}\right)$ & - & - & - & - & - & 38.6 & - & - & 95 & - & 167.9 & - & - \\
\hline Only Biomass & - & - & - & - & - & - & 20.2 & - & 52 & - & - & 21.8 & - \\
\hline Only Hydro & - & - & - & - & - & - & - & - & 43 & - & - & - & 9.3 \\
\hline VRE-1 & - & - & - & - & - & 34.5 & - & - & 100 & 25.0 & 208.1 & - & - \\
\hline VRE-2 & - & - & - & - & 25.0 & 37.7 & - & - & $100 \%$ & 315.8 & 73.5 & - & - \\
\hline VRE-3 & - & - & - & - & - & 34.5 & - & - & 100 & - & 208.1 & - & - \\
\hline VRE-4 & - & - & - & - & - & 38.6 & - & - & 100 & 207.2 & 103.3 & - & - \\
\hline VRE-5 & - & - & - & - & - & 34.5 & - & - & 100 & - & 208.1 & - & - \\
\hline VRE-6 & - & - & - & - & - & 38.6 & - & - & 100 & 89.3 & 147.2 & - & - \\
\hline Seasonal RE Only & - & - & - & - & - & - & 20.2 & 1.2 & $57 \%$ & - & - & 21.8 & 9.3 \\
\hline LC-1 & - & - & - & - & - & 34.5 & - & - & 100 & 25.0 & 208.1 & - & - \\
\hline LC-2 & - & - & - & - & 25.0 & 37.7 & - & - & 100 & 315.8 & 73.5 & - & - \\
\hline LC-3 & - & - & - & - & - & 34.5 & - & - & 100 & - & 208.1 & - & - \\
\hline LC-4 & - & - & - & - & - & 38.6 & - & - & 100 & 154.9 & 86.9 & 20.2 & 1.2 \\
\hline LC-5 & - & - & - & - & - & 34.5 & - & - & 100 & - & 208.1 & - & - \\
\hline LC-6 & - & - & - & - & - & 38.6 & - & - & 100 & 56.5 & 131.4 & 20.2 & 1.2 \\
\hline
\end{tabular}

Bold values indicate the scenarios where the $100 \%$ target is achieved 
Table 12 Cumulative energy generation for Bohol RE capacity addition under HRE generation scenario, GWh

\begin{tabular}{|c|c|c|c|c|c|c|c|c|c|c|c|c|c|}
\hline \multirow[t]{2}{*}{ Capacity addition scenario } & \multicolumn{4}{|c|}{$35 \% \mathrm{RE}$} & \multicolumn{4}{|c|}{$50 \% \mathrm{RE}$} & \multirow{2}{*}{$\begin{array}{l}\text { Max \%RE } \\
\text { Share (\%) }\end{array}$} & \multicolumn{4}{|c|}{ Max $\%$ RE } \\
\hline & Solar & Wind & Bio & Hydro & Solar & Wind & Bio & Hydro & & Solar & Wind & Bio & Hydro \\
\hline Only Solar PV (100 MW/km²) & - & - & - & - & 145 & - & - & - & 100 & 660 & - & - & - \\
\hline Only Solar PV (30 MW/km²) & - & - & - & - & 125 & - & - & - & 100 & 630 & - & - & - \\
\hline Only Solar PV (7.5 MW/ $\left.\mathrm{km}^{2}\right)$ & - & - & - & - & 123 & - & - & - & 62 & 246 & - & - & - \\
\hline Only Wind $\left(9 \mathrm{MW} / \mathrm{km}^{2}\right)$ & - & - & - & - & - & 129 & - & - & 100 & - & 709 & - & - \\
\hline Only Wind (2.25 MW/km²) & - & - & - & - & - & 125 & - & - & $95 \%$ & - & 564 & - & - \\
\hline Only Biomass & - & - & - & - & - & - & 128 & - & $52 \%$ & - & - & 138 & - \\
\hline Only Hydro & - & - & - & - & - & - & - & - & 43 & - & - & - & 51 \\
\hline VRE-1 & - & - & - & - & - & 129 & - & - & 100 & 32 & 709 & - & - \\
\hline VRE-2 & - & - & - & - & 32 & 122 & - & - & 100 & 404 & 242 & - & - \\
\hline VRE-3 & - & - & - & - & - & 129 & - & - & 100 & - & 709 & - & - \\
\hline VRE-4 & - & - & - & - & - & 125 & - & - & 100 & 265 & 353 & - & - \\
\hline VRE-5 & - & - & - & - & - & 129 & - & - & 100 & - & 709 & - & - \\
\hline VRE-6 & - & - & - & - & - & 125 & - & - & 100 & 114 & 503 & - & - \\
\hline Seasonal RE Only & - & - & - & - & - & - & 128 & 7 & $57 \%$ & - & - & 138 & 51 \\
\hline LC-1 & - & - & - & - & - & 129 & - & - & 100 & 32 & 709 & - & - \\
\hline LC-2 & - & - & - & - & 32 & 122 & - & - & 100 & 404 & 242 & - & - \\
\hline LC-3 & - & - & - & - & - & 129 & - & - & 100 & - & 709 & - & - \\
\hline LC-4 & - & - & - & - & - & 125 & - & - & 100 & 198 & 290 & 128 & 7 \\
\hline LC-5 & - & - & - & - & - & 129 & - & - & 100 & - & 709 & - & - \\
\hline LC-6 & - & - & - & - & - & 125 & - & - & 100 & 72 & 451 & 128 & 7 \\
\hline
\end{tabular}

Bold values indicate the scenarios where the $100 \%$ target is achieved

Table 13 Cumulative capacity addition for Bohol province under the HRE-RDPP generation scenario, MW

\begin{tabular}{|c|c|c|c|c|c|c|c|c|c|c|c|c|c|}
\hline \multirow[t]{2}{*}{ capacity addition Scenario } & \multicolumn{4}{|c|}{$35 \% \mathrm{RE}$} & \multicolumn{4}{|c|}{$50 \% \mathrm{RE}$} & \multirow{2}{*}{$\begin{array}{l}\text { Max \%RE } \\
\text { Share (\%) }\end{array}$} & \multicolumn{4}{|c|}{ Max $\% \mathrm{RE}$} \\
\hline & Solar & Wind & Bio & Hydro & Solar & Wind & Bio & Hydro & & Solar & Wind & Bio & Hydro \\
\hline Only Solar PV (100 MW/km²) & - & - & - & - & 95.0 & - & - & - & 100 & 516.3 & - & - & - \\
\hline Only Solar PV (30 MW/km²) & - & - & - & - & 90.3 & - & - & - & 100 & 478.0 & - & - & - \\
\hline Only Solar PV (7.5 MW/km²) & - & - & - & - & 89.3 & - & - & - & 63 & 192.2 & - & - & - \\
\hline Only Wind $\left(9 \mathrm{MW} / \mathrm{km}^{2}\right)$ & - & - & - & - & - & 34.5 & - & - & $100 \%$ & - & 208.1 & - & - \\
\hline Only Wind $\left(2.25 \mathrm{MW} / \mathrm{km}^{2}\right)$ & - & - & - & - & - & 37.7 & - & - & $96 \%$ & - & 167.9 & - & - \\
\hline Only Biomass & - & - & - & - & - & - & 20.2 & - & $52 \%$ & - & - & 21.8 & - \\
\hline Only Hydro & - & - & - & - & - & - & - & - & $44 \%$ & - & - & - & 9.3 \\
\hline VRE-1 & - & - & - & - & - & 34.5 & - & - & $100 \%$ & 25.0 & 208.1 & - & - \\
\hline VRE-2 & - & - & - & - & - & 37.7 & - & - & $100 \%$ & 315.8 & 73.5 & - & - \\
\hline VRE-3 & - & - & - & - & - & 34.5 & - & - & $100 \%$ & - & 208.1 & - & - \\
\hline VRE-4 & - & - & - & - & - & 37.7 & - & - & $100 \%$ & 207.2 & 100.9 & - & - \\
\hline VRE-5 & - & - & - & - & - & 34.5 & - & - & $100 \%$ & - & 208.1 & - & - \\
\hline VRE-6 & - & - & - & - & - & 37.7 & - & - & $100 \%$ & 89.3 & 147.2 & - & - \\
\hline Seasonal RE Only & - & - & - & - & - & - & 17.2 & 1.2 & $58 \%$ & - & - & 21.8 & 9.3 \\
\hline LC-1 & - & - & - & - & - & 34.5 & - & - & $100 \%$ & 25.0 & 208.1 & - & - \\
\hline LC-2 & - & - & - & - & - & 37.7 & - & - & $100 \%$ & 315.8 & 73.5 & - & - \\
\hline LC-3 & - & - & - & - & - & 34.5 & - & - & $100 \%$ & - & 208.1 & - & - \\
\hline LC-4 & - & - & - & - & - & 37.7 & - & - & $100 \%$ & 154.9 & 86.9 & 20.2 & 1.2 \\
\hline LC-5 & - & - & - & - & - & 34.5 & - & - & $100 \%$ & - & 208.1 & - & - \\
\hline LC-6 & - & - & - & - & - & 37.7 & - & - & $100 \%$ & 56.5 & 131.4 & 20.2 & 1.2 \\
\hline
\end{tabular}

Bold values indicate the scenarios where the $100 \%$ target is achieved 
Table 14 Cumulative energy generation for Bohol RE capacity addition under the HRE generation scenario, GWh

\begin{tabular}{|c|c|c|c|c|c|c|c|c|c|c|c|c|c|}
\hline \multirow[t]{2}{*}{ Capacity addition scenario } & \multicolumn{4}{|c|}{$35 \% \mathrm{RE}$} & \multicolumn{4}{|c|}{$50 \% \mathrm{RE}$} & \multirow{2}{*}{$\begin{array}{l}\text { Max \%RE } \\
\text { Share (\%) }\end{array}$} & \multicolumn{4}{|c|}{ Max \%RE } \\
\hline & Solar & Wind & Bio & Hydro & Solar & Wind & Bio & Hydro & & Solar & Wind & Bio & Hydro \\
\hline Only Solar PV (100 MW/km²) & - & - & - & - & 122 & - & - & - & 100 & 660 & - & - & - \\
\hline Only Solar PV (30 MW/km²) & - & - & - & - & 115 & - & - & - & 100 & 611 & - & - & - \\
\hline Only Solar PV (7.5 MW/km²) & - & - & - & - & 114 & - & - & - & 63 & 246 & - & - & - \\
\hline Only Wind $\left(9 \mathrm{MW} / \mathrm{km}^{2}\right)$ & - & - & - & - & - & 129 & - & - & 100 & - & 709 & - & - \\
\hline Only Wind (2.25 MW/km²) & - & - & - & - & - & 122 & - & - & 96 & - & 564 & - & - \\
\hline Only Biomass & - & - & - & - & - & - & 128 & - & 52 & - & - & 138 & - \\
\hline Only Hydro & - & - & - & - & - & - & - & - & 44 & - & - & - & 51 \\
\hline VRE-1 & - & - & - & - & - & 129 & - & - & 100 & 32 & 709 & - & - \\
\hline VRE-2 & - & - & - & - & - & 122 & - & - & 100 & 404 & 242 & - & - \\
\hline VRE-3 & - & - & - & - & - & 129 & - & - & 100 & - & 709 & - & - \\
\hline VRE-4 & - & - & - & - & - & 122 & - & - & 100 & 265 & 343 & - & - \\
\hline VRE-5 & - & - & - & - & - & 129 & - & - & 100 & - & 709 & - & - \\
\hline VRE-6 & - & - & - & - & - & 122 & - & - & 100 & 114 & 503 & - & - \\
\hline Seasonal RE Only & - & - & - & - & - & - & 109 & 7 & 58 & - & - & 138 & 51 \\
\hline LC-1 & - & - & - & - & - & 129 & - & - & 100 & 32 & 709 & - & - \\
\hline LC-2 & - & - & - & - & - & 122 & - & - & 100 & 404 & 242 & - & - \\
\hline LC-3 & - & - & - & - & - & 129 & - & - & 100 & - & 709 & - & - \\
\hline LC-4 & - & - & - & - & - & 122 & - & - & 100 & 198 & 290 & 128 & 7 \\
\hline LC-5 & - & - & - & - & - & 129 & - & - & 100 & - & 709 & - & - \\
\hline LC-6 & - & - & - & - & - & 122 & - & - & 100 & 72 & 451 & 128 & 7 \\
\hline
\end{tabular}

Bold values indicate the scenarios where the $100 \%$ target is achieved

\section{LCOE}

The LCOE of all modeled renewable projects varies with the capacity factor, the economics of the particular technology, and their corresponding distances from the existing transmission infrastructure and road network. It appeared that Bohol's RE portfolio could be dominated by VREs, particularly wind projects (see Tables 7, 8, 9, 10, 11, 12, 13 and 14). This is because wind projects have the lowest site-LCOE at $1.48 \mathrm{Php} / \mathrm{kWh}$ and that some of the potential wind projects in the province are located along with the existing transmission grid and highways. Although several solar PV projects are also located close to the grid and roads, they have a siteLCOE of approximately 3.44 Php/ kWh-more than twice as much as the wind. Biopower facilities are chosen near the existing grid and highways; however, their site-LCOE is more than thrice that of solar at $5.55 \mathrm{Php} / \mathrm{kWh}$. Hydropower projects have site-LCOE of $4.96 \mathrm{Php} / \mathrm{kWh}$, but only one of them is located close to the grid. Even when distances from the road network and existing transmission line are considered, wind projects also came the most economical options (see Fig. 8). Solar PV then follows, provided that they are closer to the grid.

Meanwhile, for the target 35\% RE, weighted LCOE may vary between 2.28 and $7.31 \mathrm{Php} / \mathrm{kWh}$ under BAU and BAURDPP generation scenarios (Tables 15 and 16). When only solar PV technologies are considered, a project with the highest total LCOE of $9.78 \mathrm{Php} / \mathrm{kWh}$ can be included in the portfolio. In contrast, a wind project closest to the grid came the least-cost option in these scenarios (1.99 Php/kWh). For the target 50\% RE, weighted LCOE can also vary from 2.53 to $11.38 \mathrm{Php} / \mathrm{kWh}$ under the same scenario, including a solar project at an LCOE of $22.80 \mathrm{Php} / \mathrm{kWh}$ - the highest. The $100 \%$ target can also be achieved at an LCOE ranging from 3.18 to $7.36 \mathrm{Php} / \mathrm{kWh}$. Under HRE and HRE-RDPP generation scenarios, weighted LCOE for the 50\% target can vary between 2.28 and $7.31 \mathrm{Php} / \mathrm{kWh}$ (Tables 17 and 18). The same solar project with a total LCOE of $9.78 \mathrm{Php} / \mathrm{kWh}$ can be included in the portfolio. For the theoretical 100\% RE, weighted LCOE can vary between 3.18 and $7.46 \mathrm{Php} / \mathrm{kWh}$ under these scenarios.

\section{GHG emission reduction}

When the country's RE penetration continues and the domestic oil-based power plant in Dampas continues its operation, GHG emission reduction for the target 35\% RE share can vary between 115,700 and 132,300 tCO2e (Table 15). However, when this power plant is retired, GHG emission reduction lower boundary is reduced to 113,400 tCO2e (Table 16). Under both scenarios, GHG emission reduction can vary between 221,400 and $265,500 \mathrm{tCO}_{2} \mathrm{e}$ for 


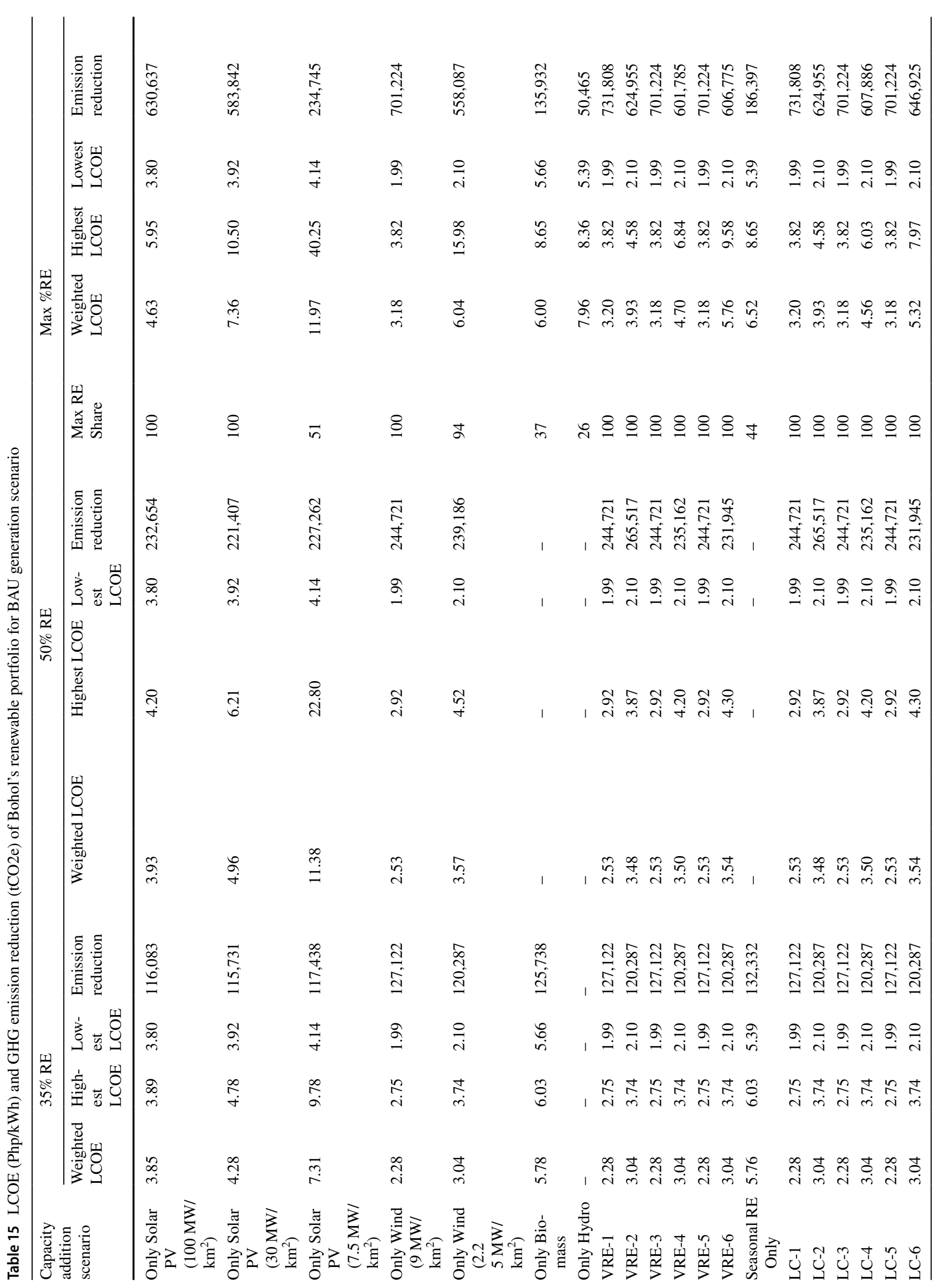




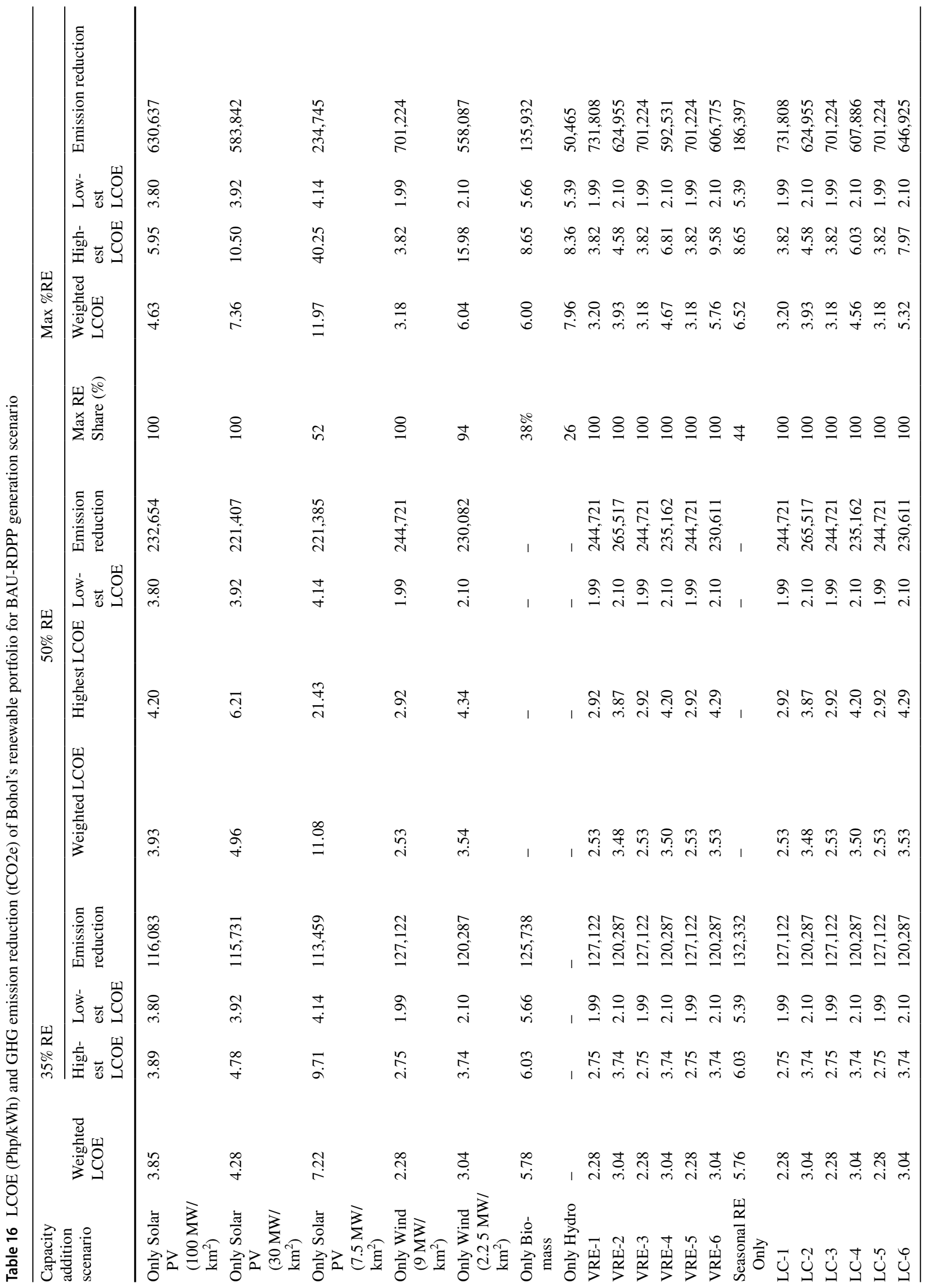




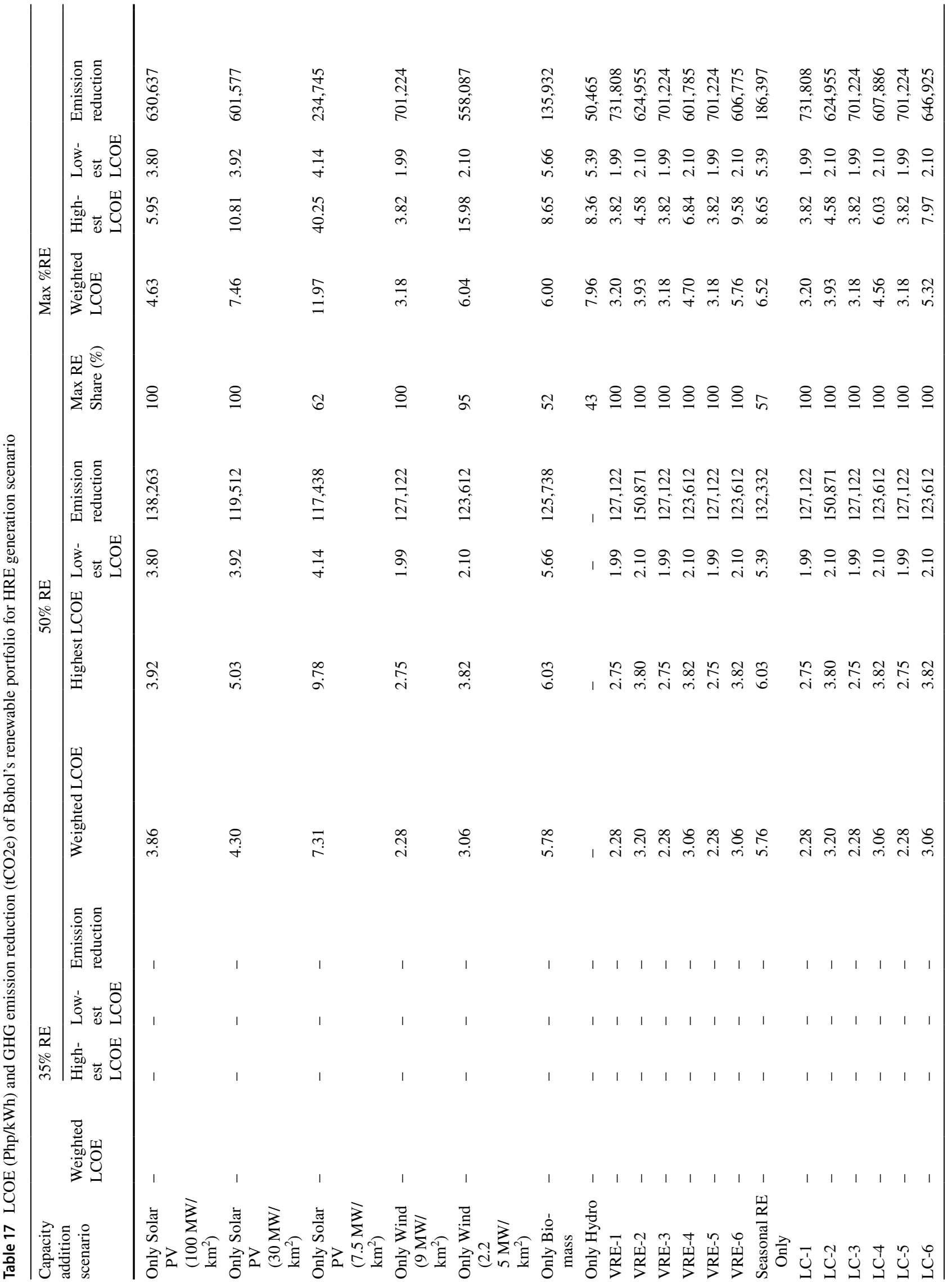




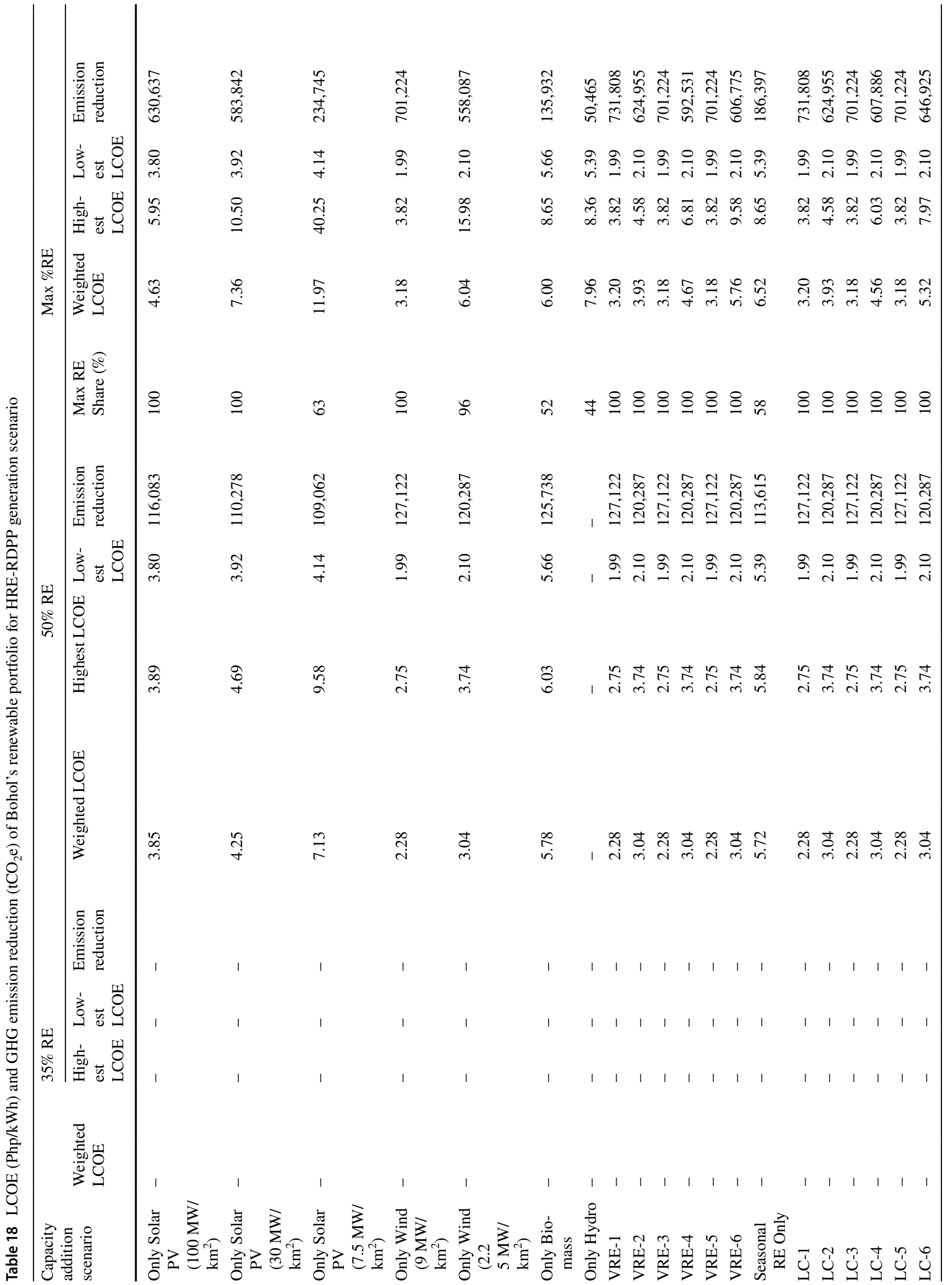


the 50\% target and between 583,800 and 732,800 $\mathrm{tCO}_{2} \mathrm{e}$ for the theoretical 100\% target. Meanwhile, when the country's RE penetration reaches 35\% with new capacities deployed in other provinces, GHG emission reduction for the $50 \%$ target can vary between 117,400 and 150,800 tCO2e, and between 601,500 and $731,800 \mathrm{tCO}_{2} \mathrm{e}$ for the theoretical $100 \%$ target (see Table 17). However, when the oil-based power plant is retired, lower boundaries reduce to $110,200 \mathrm{tCO} 2 \mathrm{e}$ and 583,800 tCO2e for the target $50 \%$ and theoretical $100 \%$, respectively (Table 18).

\section{Retirement of Dampas oil-based power plant}

Our evaluation of base cases for RE penetration in Bohol initially suggests that the oil-based power located in Dampas District, Tagbilaran City, has a little overall effect in the province's RE penetration (see Fig. 10 and Table 6). As the RE share of the province increases, this effect is expected to reduce. For instance, when this facility continues to operate by 2030 , the province's RE share was estimated at $37.29 \%$ if only biomass resources are considered, and the country's RE penetration continues. On its retirement, Bohol's RE share was estimated at $37.67 \%$. Also, if only solar PVs are considered at a power density of $7.5 \mathrm{MW} / \mathrm{km}^{2}$ under the same assumption of the country's RE penetration, the province's RE share is calculated at $51.49 \%$ when it is operated and $51.85 \%$ on its retirement. Moreover, we have seen little differences in the Bohol's RE portfolios (Table 7 vs Tables 9, 11 and 13), suggesting that this facility's retirement also has little effect.

\section{Effects of varying the power density to weighted LCOE}

In this study, we found that varying the power density had little effect on the LCOE of any given RE project, but had a significant impact on the weighted LCOE of the portfolio. In one end, site and interconnection LCOE are independent of the capacity estimates and, thus, when the power density of a given project is varied, only the road LCOE varies. On the other end, the variation in power density will affect the project's estimated full capacity and its annual energy generation and, therefore, the number of projects required for the portfolio.

Let us take the case of solar PV projects. The LCOE of all 103 solar PV projects ranges from 3.80 to $40.25 \mathrm{Php} /$ $\mathrm{kWh}$ in three different power density assumptions. To supply Bohol with RE between 118 and 121 GWh per year and reach a 35\% share, solar PV projects with LCOE ranging from 3.80 to $3.89 \mathrm{Php} / \mathrm{kWh}$ at a weighted LCOE of 3.85 $\mathrm{Php} / \mathrm{kWh}$ must be developed on the assumption of $100 \mathrm{MW} /$ $\mathrm{km}^{2}$ power density (see Tables 15 and 16). However, on an assumption of $30 \mathrm{MW} / \mathrm{km}^{2}$ and $7.5 \mathrm{MW} / \mathrm{km}^{2}$ power densities, solar projects more distant from the grid and road have to be included in the portfolio to achieve the targeted energy generation. Consequently, the LCOE range changes: 3.92 to $4.78 \mathrm{Php} / \mathrm{kWh}$ at a weighted LCOE of $4.28 \mathrm{Php} / \mathrm{kWh}$ on a power density of $30 \mathrm{MW} / \mathrm{km}^{2}$, and 4.14 to $9.78 \mathrm{Php} / \mathrm{kWh}$ at a weighted LCOE of $7.22 \mathrm{Php} / \mathrm{kWh}$ on a power density of $7.5 \mathrm{MW} / \mathrm{km}^{2}$.

\section{Challenges and opportunities in VRE integration: a brief note}

Voltage fluctuation, frequency oscillation, and harmonics are the main power quality issues of VRE integration brought by its intermittent nature [70]. Curtailment, reserves, storage, and system stability are the significant challenges that will come into the future Philippine grid considering high RE targets. A study conducted by the USAID and the Department of Energy [71] revealed that the country's existing power system could handle an RE penetration of up to $50 \%$ with a curtailment of less than $8 \%$. It would only take coordinated planning of generation and transmission development, as well as additional reserve facilities. With high VREs, system flexibility to accommodate the variability in the supply and demand is often the most pressing concern, alongside energy production costs [72]. Meanwhile, the temporal complementarity VRE projects in Bohol and spatial complementarity in the context of the entire country [73] may create a more favorable condition towards the integration of even deeper targets. These are opportunities for further studies.

\section{Conclusion}

Our spatial analysis revealed that the technical potential of domestic RE resources in Bohol is more than enough to reach the 35\% RE share. Depending on the assumption of power density for VREs, the total capacity of all modeled renewable projects ranges between 391 and $3265 \mathrm{MW}$ capable of producing $999 \mathrm{GWh}$ to $5724 \mathrm{GWh}$ annually. Bohol's energy purchase by 2030 is estimated at $600 \mathrm{GWh}$, so the RE portfolio can be any combination of solar PV, wind, biopower, and hydropower projects.

Our analysis of Bohol province base cases revealed that Bohol's RE share is always higher than that of the country's. It can be attributed to the three domestic hydropower facilities which have generated energy at a domestically higher RE share than the country. When the country's RE penetration continues, its RE share was estimated at $15.49 \%$. At this percentage, Bohol's base RE share can be $19.13 \%$. Meanwhile, when the country's RE penetration reaches $35 \%$ with new RE facilities installed outside the province, Bohol's base RE share can be $37.70 \%$. 
It also appeared that not all capacity addition scenarios have the potential to attain all the targets. For instance, when the country's RE penetration continues, it is possible to meet the $35 \%$ RE share in all scenarios except when only hydro is considered (up to $26 \%$ only). In this target, weighted LCOE can vary between 2.28 and $7.31 \mathrm{Php} / \mathrm{kWh}$ and the GHG emission reduction is approximately 120,000 tCO2e. The higher $50 \%$ target is only possible if VRE projects are included in the portfolio, while SRE projects are not enough to reach this target. In this target, weighted LCOE can vary from 2.53 to $11.38 \mathrm{Php} / \mathrm{kWh}$, while the GHG emission reduction is around 240,000 tCO2e. Meanwhile, when the country's RE penetration reaches $35 \%$ with new generation facilities located outside the province, Bohol's domestic and imported RE is already enough to meet the target (37.7\%). In this case, the province can aspire for higher targets such as 50\%, utilizing its domestic RE resources. It is possible to meet the said target at weighted LCOE which varies between 2.28 and $7.31 \mathrm{Php} / \mathrm{kWh}$ in all scenarios except when only hydropower is considered. It is also possible to self-sustain energy production for the province's demand in all scenarios with VRE projects in it.

We also found that retirement of the existing oil-based domestic generating capacity has little effect on the renewable portfolio and the province's RE share. Despite this finding, this power plant energizes the province's load center serving emergency facilities during the month-long power outages brought by typhoon Haiyan and the magnitude 7.1 earthquake in 2013. Thus, this facility is valuable until the Cebu-Bohol interconnection will come online, despite its contribution to the country's GHG emissions.

Finally, we find that the varying the power densities of variable REs have little effect on the total LCOE of a particular project because it only affects the smaller road component of LCOE. However, varying the power density will vary the capacity and energy generation of a given project and, thus, the number of projects required in the portfolio. Therefore, RE projects located more distant from the grid (usually with high LCOE) can be included in the portfolio, and the weighted LCOE may rise. The range of power density in the literature (especially for VREs) is broad, and our findings may inform researchers and energy planners about its possible impact.

Acknowledgements The main author of this study is grateful for the scholarship grant from the Department of Science and Technology-Engineering Research and Development for Technology (DOSTERDT) and the support of the CHED Newton Fund Project of the Center for Research in Energy Systems and Technologies (CREST) of the University of San Carlos, Cebu City, Philippines. A special acknowledgement to the Bohol Island State University-Main Campus and the Provincial Government of Bohol for the indispensable support; to Engr. Ernest Noel Socong and his team, who digitized the areas with settlements of the study area and the boundaries of 30 existing utility-scale solar PV projects in the country; to Engr. Jeffrey Cepedoza and other CREST researchers who digitized the transmission lines of the study area; and to Dr. Ivy Corazon Mangaya-ay for her valuable contribution to the revision of this paper.

Funding This study was conducted under the main author's scholarship grant from the Philippines Department of Science and Technology Engineering Research and Development for Technology Program.

Availability of data The data that support the findings of this study are openly available in Mendeley Data at https://dx.doi.org/10.17632 192xb8tnr9x.2. All calculations in this study were conducted in an interactive Microsoft Excel program. It is available on request from the principal author.

\section{Compliance with ethical standards}

Conflict of interest The authors declare no conflict of interest.

\section{References}

1. Department of Energy: Providing rules and guidelines governing the establishment of the Renewable Portfolio Standard (RPS). Taguig City, Philippines, (2017)

2. Department of Energy, "2019 Power Statistics," 2020. [Online]. https://www.doe.gov.ph/sites/default/files/pdf/energy_statistics /2019_power_statistic_03_gross_generation_per_plant_Type_ per_grid.pdf. Accessed 30 Jun 2020

3. BEDAG-TWG: "Bohol Island Power Development Plan 20162045," Bohol Provincial Planning and Development Office, Tagbilaran City, Philippines (2018)

4. Department of Energy, "2019 Power Statistics," 2020. [Online]. https://www.doe.gov.ph/sites/default/files/pdf/energy_statistics 12019_power_statistic_09_monthly_system_peak_demand_per_ visayas_sub_grid.pdf. Accessed 30 Jun 2020

5. Van Dael, M., Van Passel, S., Pelkmans, L., Guisson, R., Swinnen, G., Schreurs, E.: Determining potential locations for biomass valorization using a macro screening approach. Biomass Bioenergy 45, 175-186 (2012)

6. Baseer, M.A., Rehman, S., Meyer, J.P., Alam, M.M.: GIS-based site suitability analysis for wind farm development in Saudi Arabia. Energy 141, 1166-1176 (2017)

7. Jangid, J., et al.: Potential zones identification for harvesting wind energy resources in desert region of India-A multi criteria evaluation approach using remote sensing and GIS. Renew. Sustain. Energy Rev. 65, 1-10 (2016)

8. Höfer, T., Sunak, Y., Siddique, H., Madlener, R.: Wind farm siting using a spatial Analytic Hierarchy Process approach: a case study of the Städteregion Aachen. Appl. Energy 163, 222-243 (2016)

9. Tegou, L.I., Polatidis, H., Haralambopoulos, D.A.: Environmental management framework for wind farm siting: Methodology and case study. J. Environ. Manage 91, 2134-2147 (2010)

10. Uyan, M.: GIS-based solar farms site selection using analytic hierarchy process (AHP) in Karapinar region, Konya/Turkey. Renew. Sustain. Energy Rev. 28, 11-17 (2013)

11. Ali, S., Taweekun, J., Techato, K., Waewsak, J., Gyawali, S.: GIS based site suitability assessment for wind and solar farms in Songkhla, Thailand. Renew. Energy 132, 1360-1372 (2019)

12. Watson, J.J.W., Hudson, M.D.: Landscape and Urban Planning Regional Scale wind farm and solar farm suitability assessment using GIS-assisted multi-criteria evaluation. Landsc. Urban Plan. 138, 20-31 (2015) 
13. Vasileiou, M., Loukogeorgaki, E., Vagiona, D.G.: GIS-based multi-criteria decision analysis for site selection of hybrid offshore wind and wave energy systems in Greece. Renew. Sustain. Energy Rev. 73, 745-757 (2017)

14. Konstantinos, I., Georgios, T., Garyfalos, A.: A Decision Support System methodology for selecting wind farm installation locations using AHP and TOPSIS: Case study in Eastern Macedonia and Thrace region, Greece. Energy Policy 132, 232-246 (2019)

15. Atici, K.B., Simsek, A.B., Ulucan, A., Tosun, M.U.: A GIS-based Multiple Criteria Decision Analysis approach for wind power plant site selection. Util. Policy 37, 86-96 (2015)

16. M. Tavana, F. J. SantosArteaga, S. Mohammadi, and M. Alimohammadi, "A fuzzy multi-criteria spatial decision support system for solar farm location planning," Energy Strateg. Rev., vol. 18, pp. 93-105, 2017.

17. Shorabeh, S.N., Firozjaei, M.K., Nematollahi, O., Firozjaei, H.K., Jelokhani-Niaraki, M.: A risk-based multi-criteria spatial decision analysis for solar power plant site selection in different climates: A case study in Iran. Renew. Energy 143, 958-973 (2019)

18. Noorollahi, Y., Yousefi, H., Mohammadi, M.: Multi-criteria decision support system for wind farm site selection using GIS. Sustain. Energy Technol. Assess. 13, 38-50 (2016)

19. Ayodele, T.R., Ogunjuyigbe, A.S.O., Odigie, O., Munda, J.L.: A multi-criteria GIS based model for wind farm site selection using interval type-2 fuzzy analytic hierarchy process: The case study of Nigeria. Appl. Energy 228, 1853-1869 (2018)

20. Sánchez-lozano, J.M., García-cascales, M.S., Lamata, M.T.: GISbased onshore wind farm site selection using Fuzzy Multi-Criteria Decision Making methods. Evaluating the case of Southeastern Spain. Appl. Energy 171, 86-102 (2016)

21. Villacreses, G., Gaona, G., Martínez-Gómez, J., Jijón, D.J.: Wind farms suitability location using geographical information system (GIS), based on multi-criteria decision making (MCDM) methods: The case of continental Ecuador. Renew. Energy 109, 275-286 (2017)

22. Vafaeipour, M., Zolfani, S.H., Varzandeh, M.H.M., Derakhti, A., Eshkalag, M.K.: Assessment of regions priority for implementation of solar projects in Iran: New application of a hybrid multicriteria decision making approach. Energy Convers. Manag. 86, 653-663 (2014)

23. Perpiña Castillo, C., Batista e silva, F., Lavalle, C.: "An assessment of the regional potential for solar power generation in EU-28. Energy Policy 88, 86-99 (2016)

24. Mahdy, M., Bahaj, A.B.S.: Multi criteria decision analysis for offshore wind energy potential in Egypt. Renew. Energy 118, 278-289 (2018)

25. Mensour, O.N., El Ghazzani, B., Hlimi, B., Ihlal, A.: A geographical information system-based multi-criteria method for the evaluation of solar farms locations: a case study in Souss-Massa area, southern Morocco. Energy 182, 900-919 (2019)

26. Gavériaux, L., Laverrière, G., Wang, T., Maslov, N., Claramunt, C.: Annals of GIS GIS-based multi-criteria analysis for offshore wind turbine deployment in Hong Kong. Ann. GIS 25(3), 207218 (2019)

27. Ghasemi, G., Noorollahi, Y., Alavi, H., Marzband, M., Shahbazi, M.: Theoretical and technical potential evaluation of solar power generation in Iran. Renew. Energy 138, 1250-1261 (2019)

28. Dhunny, A.Z., Doorga, J.R.S., Allam, Z., Lollchund, M.R., Boojhawon, R.: Identification of optimal wind, solar and hybrid wind-solar farming sites using fuzzy logic modelling. Energy 188, 116056 (2019)

29. Doorga, J.R.S., Rughooputh, S.D.D.V., Boojhawon, R.: Multicriteria GIS-based modelling technique for identifying potential solar farm sites: a case study in Mauritius. Renew. Energy 133, 1201-1219 (2019)
30. Asakereh, A., Soleymani, M., Sheikhdavoodi, M.J.: A GIS-based Fuzzy-AHP method for the evaluation of solar farms locations: case study in Khuzestan province, Iran. Sol. Energy 155, 342-353 (2017)

31. Farthing, A., Carbajales-Dale, M., Mason, S., Carbajales-Dale, P., Matta, P.: Utility-Scale Solar PV in South Carolina: Analysis of Suitable Lands and Geographical Potential. Biophys. Econ. Resour. Qual. 1(2), 1-15 (2016)

32. Deshmukh, R., Wu, G.C., Callaway, D.S., Phadke, A.: Geospatial and techno-economic analysis of wind and solar resources in India. Renew. Energy 134, 947-960 (2019)

33. Pantusa, D., Tomasicchio, G.R.: Large-scale offshore wind production in the Mediterranean Sea. Cogent Eng. 6(1), 1-20 (2019)

34. Schallenberg-Rodríguez, J., Montesdeoca, N.G.: Spatial planning to estimate the offshore wind energy potential in coastal regions and islands. Practical case: The Canary Islands. Energy 143, 91-103 (2018)

35. Kim, T., Park, J., Maeng, J.: Offshore wind farm site selection study around Jeju Island, South Korea. Renew. Energy 94, 619-628 (2016)

36. Anwarzai, M.A., Nagasaka, K.: Utility-scale implementable potential of wind and solar energies for Afghanistan using GIS multi-criteria decision analysis. Renew. Sustain. Energy Rev. 71, 150-160 (2017)

37. Kim, C., Jang, S., Kim, T.Y.: Site selection for offshore wind farms in the southwest coast of South Korea. Renew. Energy 120, 151-162 (2018)

38. Polo, J., Bernardos, A., Navarro, A.A., Fernandez-peruchena, C.M., Ramírez, L., Guisado, M.V.: Solar resources and power potential mapping in Vietnam using satellite-derived and GISbased information. Energy Convers. Manag. 98, 348-358 (2015)

39. Mentis, D., Siyal, S.H., Korkovelos, A., Howells, M.: A geospatial assessment of the techno-economic wind power potential in India using geographical restrictions. Renew. Energy 97, 77-88 (2016)

40. Manomaiphiboon, K., Paton, C.P., Prabamroong, T., Rajpreeja, N., Assareh, N., Siriwan, M.: Wind energy potential analysis for Thailand: Uncertainty from wind maps and sensitivity to turbine technology. Int. J. Green Energy 14(6), 528-539 (2017)

41. Wong, M.S., et al.: Estimation of Hong Kong's solar energy potential using GIS and remote sensing technologies. Renew. Energy 99, 325-335 (2016)

42. Kusre, B.C., Baruah, D.C., Bordoloi, P.K., Patra, S.C.: Assessment of hydropower potential using GIS and hydrological modeling technique in Kopili River basin in Assam (India). Appl. Energy 87, 298-309 (2010)

43. Bódis, K., Monforti, F., Szabó, S.: Could Europe have more mini hydro sites? A suitability analysis based on continentally harmonized geographical and hydrological data. Renew. Sustain. Energy Rev. 37, 794-808 (2014)

44. Pandey, A., Lalrempuia, D., Jain, S.K.: Assessment of hydropower potential using spatial technology and SWAT modelling in the Mat River, southern Mizoram, India. Hydrol. Sci. J. 60(10), 1651-1665 (2015)

45. Tarife, R.P., Tahud, A.P., Gulben, E.J.G., Macalisang, H.A.R.C.P., Ignacio, M.T.T.: Application of geographic information system (GIS) in hydropower resource assessment: a case study in Misamis Occidental, Philippines. Int. J. Environ. Sci. Dev. 8(7), 507-511 (2017)

46. Garegnani, G., Sacchelli, S., Balest, J., Zambelli, P.: GIS-based approach for assessing the energy potential and the financial feasibility of run-off-river hydropower in Alpine valleys. Appl. Energy 216, 709-723 (2018) 
47. Beccali, M., Columba, P., Alberti, V.D., Franzitta, V.: Assessment of bioenergy potential in Sicily: A GIS-based support methodology. Biomass Bioenerg. 33, 79-87 (2009)

48. Grilli, G., Garegnani, G., Geri, F., Ciolli, M.: Cost-benefit analysis with GIS: an open source module for the forest bioenergy sector. Energy Procedia 107, 175-179 (2017)

49. Teixeira, T.R., et al.: Forest biomass power plant installation scenarios. Biomass Bioenerg. 108, 35-47 (2018)

50. Lopez, A., Roberts, B., Heimiller, D., Blair, N., Porro, G.: U.S. renewable energy technical potentials: a GIS-based analysis. National Renewable Energy Laboratory (2012). Available: https ://www.nrel.gov/docs/fy12osti/51946.pdf. Accessed 2 Dec 2020

51. Deng, Y.Y., et al.: Quantifying a realistic, worldwide wind and solar electricity supply. Glob. Environ. Chang. 31, 239-252 (2015)

52. Nagababu, G., Kachhwaha, S.S., Savsani, V.: Estimation of technical and economic potential of offshore wind along the coast of India. Energy 138, 79-91 (2017)

53. Hong, L., Möller, B.: Offshore wind energy potential in China: Under technical, spatial and economic constraints. Energy 36, 4482-4491 (2020)

54. Soulouknga, M.H., Oyedepo, S.O., Doka, S.Y., Kofane, T.C.: Evaluation of the cost of producing wind-generated electricity in Chad. Int. J. Energy Environ. Eng. 11(2), 275-287 (2020)

55. Ohunakin, O.S., Oyewola, O.M., Adaramola, M.S.: Economic analysis of wind energy conversion systems using levelized cost of electricity and present value cost methods in Nigeria. Int. J. Energy Environ. Eng. 4(2), 2-9 (2013)

56. Ram, M., Child, M., Aghahosseini, A., Bogdanov, D., Lohrmann, A., Breyer, C.: A comparative analysis of electricity generation costs from renewable, fossil fuel and nuclear sources in G20 countries for the period 2015-2030. J. Clean. Prod. 199, 687-704 (2018)

57. Maclaurin, G., et al.: The Renewable Energy Potential (reV) model: a geospatial platform for technical potential and supply curve modeling. National Renewable Energy Laboratory (2019). Available: https://www.nrel.gov/docs/fy19osti/73067.pdf. Accessed 2 Dec 2020

58. Wu, G.C., Deshmukh, R., Ndhlukula, K., Radojicic, T., Reilly, J.: Renewable energy zones for the Africa clean energy corridor. International Renewable Energy Agency and Lawrence Berkeley National Laboratory, LBNL report number 187271 (2015). Available: https://www.irena.org/-/media/Files/IRENA /Agency/Publication/2015/IRENA-LBNL_Africa-RE-_ CEC_2015.pdf. Accessed 2 Dec 2020
59. The World Bank: "Solar resource data: Solargis. (2019)

60. Ramachandra, T.V., Krishna, S.V., Shruthi, B.V.: Decision support system to assess regional biomass energy Potential. Int. J. Green Energy 1(4), 407-428 (2005)

61. Manzano-Agugliaro, F., Taher, M., Zapata-Sierra, A., Juaidi, A., Montoya, F.G.: An overview of research and energy evolution for small hydropower in Europe. Renew. Sustain. Energy Rev. 75, 476-489 (2017)

62. IRENA: Renewable Power Generation Costs in 2017. International Renewable Energy Agency (2018)

63. New England States Committee on Electricity: Renewable Resource Supply Curve Report (2012)

64. NREL: 2019 Annual Technology Baseline (ATB) (2019)

65. Mills, A., Phadke, A., Wiser, R.: Exploration of resource and transmission expansion decisions in the Western Renewable Energy Zone initiative. Energy Policy 39(3), 1732-1745 (2011)

66. Department of Energy, "2019 Power Statistics," 2020. [Online]. Available: https://www.doe.gov.ph/sites/default/files/pdf/energ y_statistics/2019_power_statistic_04_gross_generation_per_plant _Type_per_visayas_sub_grid.pdf. Accessed: 2 Jul 2020.

67. Department of Energy: Power Development Plan 2016-2040. Taguig City, Philippines (2017)

68. Pojadas, D.J., Abundo, M.L.S.: Datasets for spatial analysis of potential inland renewable portfolio for Bohol, Philippines. Mendeley Data (2020). https://doi.org/10.17632/92xb8tnr9x.2

69. Intergovernmental Panel on Climate Change: Renewable energy sources and climate change mitigation (2012)

70. AL Badwawi, R., Abusara, M., Mallick, T.: A review of hybrid solar PV and wind energy system. Smart Sci. 3(3), 127-138 (2015)

71. USAID and the Department of Energy:"Greening the grid: Solar and Wind Grid Integration Study for the Luzon-Visayas System of the Philippines (2018)

72. Notton, G., et al.: Intermittent and stochastic character of renewable energy sources: Consequences, cost of intermittence and benefit of forecasting. Renew. Sustain. Energy Rev. 87, 96-105 (2018)

73. Jurasz, J., Canales, F.A., Kies, A., Guezgouz, M., Beluco, A.: A review on the complementarity of renewable energy sources: concept, metrics, application and future research directions. Sol. Energy 195, 703-724 (2020)

Publisher's Note Springer Nature remains neutral with regard to jurisdictional claims in published maps and institutional affiliations. 